\title{
CONSIDERACIONES ACERCA DEL \\ CONTENIDO DE ESPECIALIDAD QUE CARACTERIZA \\ A LOS SISTEMAS PENALES DE ADOLESCENTES*
}

ABOUT SPECIAL FIELD CONTENT THAT CHARACTERIZES

THE ADOLESCENT PENAL SYSTEMS

\author{
CONSIDERATIONS SUR LE CONTENU DE SPÉCIALITÉ QUI CARACTÉRISE \\ LES SYSTÈMES DU DROIT PÉNAL DES ADOLESCENTS
}

Francisco Maldonado Fuentes $^{* *}$

\begin{abstract}
RESUMEN
El artículo revisa los diversos sistemas que han sido implementados en el contexto occidental para el tratamiento en la comisión de delitos cometidos por parte de adolescentes. Se revisarán las principales características del denominado modelo clásico (o del discernimiento), del modelo tutelar (o de la situación irregular) y del llamado modelo educativo, para asumir una breve caracterización del modelo de responsabilidad especial, que es el que actualmente se promueve desde los instrumentos internacionales referidos a la materia, que ofrece modalidades satisfactorias.
\end{abstract}

PALABRAS CLAVE: Régimen penal de menores - Responsabilidad penal juvenil - Modelo responsabilidad especial - Sistema penal adolescente - Culpabilidad

\section{ABSTRACT}

The article reviews the various systems that have been implemented in the Occidental context for treatment in the commission of crimes committed by adolescents. The main features of the so called classical (or discernment), model, protective model (or the irregular situation model), and the so-called educational model will be reviewed, in order to take a brief special responsibility model characterization, which is currently being promoted from international instruments referrals to the subject, model that offers satisfactory arrangements.

KEY WORDS: Juvenile criminal regime - Juvenile criminal responsibility - Special responsibility model - Adolecent criminal system - Culpability

\section{RÉSUMÉ}

La chronique analyse différents systèmes qui ont été mise en pratique dans le contexte occidental pour le traitement dans l'exécution de délits comis pour adolescents. On envisage l'analyse des caracteristiques principales du nommé modêle classique (ou du discerniment), du môdele tuttelaire (ou de la situation irrégulière) et du môdele connu sous le nom éducatif, pour mettre en place une briève caracterisation du môdele de la responsabilité spéciale dont on peut conclure il s'agit du môdele promu actuellement par les instruments internationaux dans ce domaine, qui offre modalités satisfaisantes.

MOTS CLÈS: Régime pénal des mineurs - Responsabilité pénal adolescent-Môdele résponsabilité spéciale - Système pénale adolescente - Culpabilité

* Artículo recibido el 6 de mayo de 2014 y aceptado para su publicación el 30 de mayo de 2014.

** Abogado; Doctor en Derecho por la Universidad Pablo de Olavide, Sevilla. Profesor e investigador Facultad de Derecho de la Universidad de Talca. Subdirector del Centro de Estudios de Derecho Penal de dicha casa de Estudios. Correo electrónico: frmaldonado@utalca.cl. 


\section{INTRODUCCIÓN}

En la actualidad constituye casi un lugar común el que se sostenga que los sistemas penales deben considerar disposiciones relativas al tratamiento de los delitos cometidos por menores de edad sobre la base de modelos de responsabilidad considerados especiales. En concreto, se postula la posibilidad de hacer efectiva su responsabilidad, a pesar de su minoría de edad, en términos o bajo condiciones diversas a las que propone el sistema penal general o de adultos, orientados, fundamentalmente, por consideraciones que parecieran extraer efectos del hecho de que se trata de individuos que (aún) no cuentan con el reconocimiento de las capacidades atribuidas a los mayores de edad. Este antecedente, motivaría una particular conceptualización (y priorización) del papel que cumplen los objetivos preventivo-especiales en los efectos que se esperan obtener a partir de la intervención penal, lo que obligaría a atribuirle a los contenidos del modelo un carácter propio y particular.

No obstante, a la hora de analizar cuál es la extensión de los efectos y orientaciones concretas asociadas a dicho tratamiento, régimen o modelo especial, las opiniones parecieran carecer de toda uniformidad y, en particular, de concreción ${ }^{1}$. $\mathrm{Ni}$ siquiera existe mucha claridad a la hora de precisar el contenido concreto que asume la orientación resocializadora que caracteriza dicho tratamiento especial o la forma como se compatibiliza su papel o función con el reconocimiento de autonomía que en paralelo conlleva la afirmación de la responsabilidad penal de los adolescentes (su culpabilidad) ${ }^{2}$. Tampoco existe claridad acerca de los contenidos que diferencian dicho juicio de atribución respecto del que se emite sobre un adulto conforme al régimen penal general ${ }^{3}$.

\footnotetext{
${ }^{1}$ Destacan Couso, Jaime y DuCE, Mauricio (2013). Juzgamiento penal de adolescentes. Santiago: LOM; Hernández Basualto, Héctor (2007). "El nuevo Derecho Penal de adolescentes y la necesaria revisión de su teoría del delito". Revista de Derecho Universidad Austral de Valdivia, Vol. XX, No 2, diciembre, pp. 202 y ss.; Maldonado Fuentes, Francisco (2009). "Responsabilidad penal juvenil: estado actual y perspectivas". Disponible en: «www.microjuris.com`, cita: MJCH_MJD372 | MJD372, pp. 8 y ss. Una versión levemente actualizada ha sido publicada en Revista General de Derecho Penal, No 14, noviembre 2010.

${ }^{2} \mathrm{Al}$ respecto, la excepción la constituyen los desarrollos expuestos por Couso SALAS, Jaime (1999). Derecho Penal de adolescentes: ¿educación, ayuda o sanción? Facultad de Ciencias Sociales de la Universidad de ChileUNICEF, Santiago; y en Couso SALAS, Jaime (2002). "Problemas teóricos y prácticos del principio de separación de medidas y programas, entre la vía penal-juvenil y la vía de protección especial de derechos". En: De la tutela a la Justicia, Documentos de Estudio Corporación Opción, Santiago, pp. 72 y ss. Luego, el mismo autor Couso SALAS, Jaime (2005) "Principio educativo y (re)socialización en el Derecho Penal juvenil”. Revista de Derecho del Consejo de Defensa del Estado, No 14, pp. 57-72; y, finalmente, en Couso SALAS, Jaime (2011). "Sustitución y remisión de sanciones penales de adolescentes. Criterios y límites para las decisiones en sede de control judicial de las sanciones". En: Estudios de Derecho Penal Juvenil II, Informes en Derecho, Centro de Documentación de la Defensoría Penal Pública, diciembre, pp. 273 a 288.

${ }^{3}$ En el mismo sentido Couso y DuCE (2013), p. 25. Al respecto, como excepción en nuestro medio, el mismo texto, pp. 311 y ss. Tempranamente Hernández Basualto (2007), passim. Sobre el concepto de "culpabilidad por el hecho" en el Derecho Penal de adolescentes Cruz Márquez, Beatriz (2012). "La culpabilidad por el hecho del adolescente: referencias y diferencias respecto del Derecho Penal de adultos".
} 
De hecho, es habitual que de forma inadvertida se identifiquen dichos contenidos o la forma de resolverlos con lineamientos que históricamente se han propuesto para el tratamiento de los conflictos penales de los menores de edad y que en la actualidad son rechazados en forma generalizada (como la orientación preventivoespecial o resocializadora de los modelos tutelares, paternalistas o educativos) y que los modelos de responsabilidad especial pretenden precisamente reemplazar ${ }^{4}$.

En dicho contexto, la presente contribución pretende aportar al esclarecimiento de dichas orientaciones y de los contenidos que acorde a la experiencia histórica debiesen dar forma a dicho tratamiento especial, lo que a nuestro juicio brinda mucha utilidad para saber lo que la especialidad no es o no pretende. Para ello, nos proponemos revisar en forma separada los diversos sistemas que han sido implementados en el contexto occidental para hacer frente a la comisión de delitos por parte de adolescentes, a fin de extraer elementos de juicio que nos ayuden a determinar los caracteres e instituciones que siendo propios de sus lógicas $\mathrm{u}$ orientaciones configuran contenidos diversos a los que se pretenden obtener tras las bases o premisas que dan forma a las características de los modelos definidos por la idea de que al adolescente se le puede exigir una responsabilidad especial 5 . En este sentido, revisaremos las principales características del denominado modelo clásico (o del discernimiento); del modelo tutelar (o "de la situación irregular") y del llamado modelo educativo, para asumir finalmente, y a partir de dichos contenidos, una breve caracterización del modelo de responsabilidad especial ${ }^{6}$, que es el que actualmente se promueve desde los instrumentos internacionales referidos a la materia ${ }^{7}$ con miras a superar las perspectivas y fundamentos propuestos en los desarrollos precedentes, ofreciendo modalidades que a nuestro juicio son, a dichos efectos, plenamente satisfactorias.

En: Estudios de Derecho Penal Juvenil III, Informes en Derecho No 11, Centro de Documentación de la Defensoría Penal Pública, Santiago, pp. 9-32.

${ }^{4}$ En el mismo sentido Couso y Duce (2013), pp. 441 y 442 puede verse cita de fallos donde se aplica la idea de prevención especial positiva (de reinserción) con base en orientaciones propias del modelo tutelar. La incompatibilidad con los contenidos previstos en el artículo 20 de la Ley No 20.084, a partir de una conceptualización propia de la especialidad del modelo, se sugiere en MAÑALICH RafFo, Juan Pablo (2013). "Los plazos de prescripción de la acción penal de la ley de responsabilidad penal de adolescentes frente al artículo 369 quáter del Código Penal". En: Estudios de Derecho Penal Juvenil IV, Informes en Derecho No 13, Centro de Documentación de la Defensoría Penal Pública, Santiago, p. 220, nota 18.

${ }^{5}$ Se puede consultar un desarrollo similar pero más acotado y menos sistemático en MaLdonado FuENTES, Francisco (2004). "La especialidad del sistema de responsabilidad penal de los adolescentes. Reflexiones acerca de la justificación de un tratamiento penal diferenciado". Revista Justicia y Derechos del Niño, № 6, pp. 103-160.

${ }^{6}$ Para más detalles se puede consultar el texto de Couso y DuCE (2013) referido en las notas precedentes, que constituye el desarrollo nacional más completo sobre la materia, a partir de la vigencia de la Ley No 20.084. Tempranamente, Hernández Basualto (2007), pp. 195-217.

${ }^{7}$ Sobre ello vid. infra apartado 3. Asimismo, Couso y DucE (2013), pp. 306 y ss. 


\section{Modelos tradicionales}

\subsection{Sistema clásico}

\subsubsection{Descripción}

La primera forma de entender la especialidad del modelo penal de adolescentes, propia del periodo clásico imperante en el siglo XIX, nos propone asumir que sus diferencias con el sistema de adultos provienen en exclusiva del diverso grado de culpabilidad que es posible reconocer en los menores de edad. En concreto, se postula como premisa que el adolescente cuenta con una capacidad para reaccionar frente al mensaje que emite la norma penal que es diversa a la que presenta un adulto, en atención a que detenta un desarrollo personal y un grado de madurez inferior, resultando por ello impropio postular a su respecto una exigibilidad análoga a la prevista en el régimen general. En términos sistemáticos, se trataría de sujetos que gozan de una menor imputabilidad (“capacidad de culpabilidad") lo que lleva a una menor exigibilidad de respuesta frente al imperativo que propone la normativa penal, a la formulación de un menor reproche y, consecuentemente, a la aplicación de una sanción comparativamente menos rigurosa respecto de la que el sistema general prevé para el delito que es cometido por un adulto.

Conforme a dicha conceptualización, las legislaciones debiesen establecer diferencias en el tratamiento de la imputabilidad por razones de desarrollo personal o madurez social, considerando por un lado el caso de los infantes, en cuanto se trata de sujetos que carecen de capacidad; el régimen general común, representativo del Derecho Penal "normal"; y, finalmente, el tratamiento especial o particular que amerita el caso de los menores-adultos, en atención a que, según hemos señalado, presentan condiciones de desarrollo que obligan a atenuar su responsabilidad.

Esta comprensión del problema lleva a sostener una identidad básica y esencial en el modelo penal (sea que se aplique a adultos o a menores de edad) que, por lo mismo, no reconoce diferencias relevantes diversas a las que propone la consideración de determinadas condiciones asociadas naturalmente a la (menor) edad del infractor. Ello aplica a la configuración de los presupuestos de la imputación penal (tipos penales y teoría del delito, en general); al contenido de las consecuencias previstas (sino sólo en su comparación cuantitativa y, en especial, en su extensión) y, por supuesto, a las finalidades perseguidas con la aplicación de la pena (y por el sistema en general $^{8}$ ) en cuanto las particularidades se reflejan en exclusiva en la medida de la reacción. Con ello, no sería propio hablar de un régimen, sistema o modelo penal especial de adolescentes en propiedad, apuntando más bien el modelo a la necesidad de considerar reglas especiales que, en lo concreto, den cuenta de su

\footnotetext{
${ }^{8}$ En la actualidad pareciera bastante asentada la idea de que los fines de la pena y los fines del sistema se configuran en base a objetivos diversos. Al respecto vid. PIÑA Rochefort, Juan Ignacio (2010). Derecho Penal. Fundamentos de la responsabilidad. Santiago: AbeledoPerrot, pp. 59 y ss.
} 
imputabilidad disminuida, en particular, a la hora de regular los efectos penológicos que acarrea su (atenuada) responsabilidad'.

Como características relevantes conviene tener en cuenta, además, que se trata de una conceptualización comúnmente asociada a una perspectiva netamente retributiva del rol de la pena, no obstante recibir acogida en términos similares en los planteamientos preventivos de gestación clásica. Constituyó, además, y por lo mismo, la principal modalidad de tratamiento de la responsabilidad de los menores de edad en las corrientes que dominaron la caracterización positiva de los sistemas penales hasta el siglo XIX, con particular incidencia en el proceso de codificación ${ }^{10}$. Así, por ejemplo, se expresa en la fijación original de la capacidad de imputabilidad en los 10 años en el Código Penal chileno originario, como también en la previsión de una atenuación forzosa e importante en la pena aplicable a quienes resulten declarados responsables de la comisión de un delito ${ }^{11}$. Lo propio acontece en los códigos penales españoles del siglo XIX y con todos aquellos que recibieron su influencia en Hispanoamérica ${ }^{12}$.

\subsubsection{Valoración crítica}

La idea de que es posible reconocer a los menores de edad capacidad para responder por su comportamiento delictivo, como también el que dicha condición justifica una regla de atenuación vinculante (derivada de las diferencias presentes entre dicha capacidad con la que es propia de un adulto), constituyen premisas que

\footnotetext{
${ }^{9}$ Es efectivo que la consideración de esta "imputabilidad disminuida" puede tener incidencias en el reproche penal que es posible dirigir a un adolescente en términos de llegar a afectar que el sentido de injusto de los comportamientos por los que se lo puede responsabilizar, en una valoración de carácter global, con base a la diversa caracterización de la capacidad (imputabilidad) concurrente en éste y en un adulto. De ahí que dicha base sea apta para afirmar diferencias en los delitos y circunstancias fundantes de su responsabilidad. En este sentido Cruz Márquez (2012), pp. 12 y 17 y ss. Asimismo, Von Hirsch, Andrew (2012). "Sentencias proporcionales para menores ¿qué diferencia con las de los adultos?”. En: Estudios de Derecho Penal Juvenil III, Informes en Derecho No 11, Centro de Documentación de la Defensoría Penal Pública, Santiago, pp. 65 y ss. No obstante, se trata a nuestro juicio de consideraciones que van mucho más allá del solo contenido de la imputabilidad, como acontece en el sistema clásico, confirmando de paso el que se está pensando el modelo a partir del régimen de adultos. Por algo se habla de imputabilidad o culpabilidad disminuida en referencia a otra, de mayor entidad, que corresponde a la "normal', lo que sitúa al adolescente en una posición de "anormalidad" que nos parece objetable. Implícito en Couso y DucE (2013), pp. 316 y ss., quienes solo extraen consecuencias asociadas a la extensión de la sanción a partir de la afirmación de la culpabilidad o imputabilidad disminuida del adolescente. Explícito en la fundamentación de la especialidad que sostiene MaÑalich RafFo (2013), pp. 217, 219 y 220.

${ }^{10}$ Sus orígenes sin embargo se remontan a la antigüedad. Vid. Silva SÁnchez, Jesús María (1997). "El régimen de la minoría de edad penal”. En: El Nuevo Código Penal: Cinco Cuestiones Fundamentales, Barcelona: Bosch, pp. 165 y 166.

${ }^{11} \mathrm{Al}$ respecto el inciso $1^{\circ}$ del artículo 72 del Código Penal chileno (originalmente concebido como único y hoy derogado) disponía la rebaja obligatoria en un grado a partir del mínimo señalado en la ley en el respectivo marco penal.

${ }^{12}$ Vid. Pacheco, Joaquín Francisco (1888). El Código Penal concordado y comentado. Madrid, Tomo I, 6a edición, pp. 138 y ss.
} 
motivan una valoración ambivalente. Por un lado, hay que tener en cuenta que se trata de supuestos fundados en consideraciones plenamente relevantes y acertadas de tratar, pero también el que dichos contenidos son abordados (trabajados) en forma deficitaria (o más bien incompleta) en la medida en que no se desarrollan con profundidad todas las consecuencias que propone su consideración. Como resultado, se ofrecen conclusiones parciales que, en definitiva, resultan objetables, injustificadas o inadecuadas (según se prefiera) ${ }^{13}$.

En efecto, el reconocimiento de las capacidades de interacción social de los menores de edad, constituye un presupuesto plenamente valorable, que pone de relieve el hecho de que la minoría de edad no puede servir de excusa para privar a los adolescentes de la condición de sujetos de derecho, ni impide la consideración y atribución de efectos asociados al grado de autonomía o autodeterminación que detentan en forma natural. Hay que tener en cuenta que un amplio segmento de las personas que aún no alcanzan la mayoría de edad (en general asociado a la adolescencia y, según los ámbitos, hasta el campo de los impúberes), gozan a nivel material y normativo ${ }^{14}$ de un amplio grado de libertad para el ejercicio autónomo de las capacidades individuales cuya consideración ofrece una serie de consecuencias y efectos que resultan positivos para la caracterización del modelo. Destaca, entre ellas, el que la definición de la intervención penal con base en la responsabilidad individual, presenta ventajas comparativas para la satisfacción de los objetivos preventivos que persigue el sistema, en la medida en que deposita sus expectativas de aseguramiento en una amplia batería de interacciones (que van desde lo normativo a la ejecución material de medidas restrictivas de la libertad, incluyendo específicamente el tratamiento y aprovechamiento de la autorresponsabilidad). Además, se trata de un supuesto que ofrece argumentos de peso a la hora de legitimar la intervención penal, en cuanto permite configurarla como una reacción plenamente merecida por el individuo (consecuencia del ejercicio de su propia autonomía), atendido que la pena aparecerá fundada en la culpabilidad individual del infractor. Finalmente, constituye un reconocimiento que obliga a considerar criterios objetivos de legitimación que nutren al modelo de un contexto de racionalidad y justicia, expresado concretamente en la necesidad de que la reacción penal se imponga con plena sujeción a las garantías procesales y penales

\footnotetext{
${ }^{13}$ En relación con esto debemos considerar que se trata de una conceptualización propia de un contexto histórico que en buena medida se encuentra superado, siendo propio por ello acometer el análisis (en este caso en particular) a partir de una aproximación en perspectiva.

${ }^{14} \mathrm{Se}$ trata en efecto de una premisa que goza de bases materiales potentes toda vez que es posible sostener y corroborar la efectiva capacidad de comprensión y disposición de la voluntad respecto de los mandatos del derecho en la población adolescente y en buena parte de los impúberes, contenido que por lo demás goza de pleno reconocimiento en el nivel normativo. Baste tener en cuenta que el reconocimiento de derechos de ejecución autónoma en la minoría de edad es palpable en ámbitos patrimoniales; en el ejercicio de derechos de participación, asociación, etc., todo lo cual se expresa nítidamente además en su desempeño cotidiano.
} 
que, conforme al desarrollo actual, deben ser reconocidas a todos los individuos (sean mayores o menores de edad).

En lo fundamental, se trata de un presupuesto que permite la atribución de la responsabilidad individual y que, a su vez, limita las posibilidades de intervención del Estado, en cuanto obliga a considerar mecanismos de actuación compatibles (en contenido y orientación) con la condición y estatus personal que dicho reconocimiento conlleva y supone (el carácter de un sujeto de derechos).

El punto problemático radica en que se trata de una premisa, que en este caso en particular, es considerada a efectos de concluir una (virtual) equiparación de la posición del adolescente (o del impúber) con la condición que ofrece la mayoría de edad, a pesar de que formalmente pareciera identificarse una diferencia asociada a entidad. En concreto, se propone una dinámica de intervención en la que el menor de edad es tratado como un adulto, toda vez que se le aplica un modelo de intervención que está diseñado a partir de las capacidades atribuidas a los mayores de edad.

Hay que tener en cuenta que la lectura que ofrece la consideración de las capacidades atribuidas a los menores de edad, en este caso, es la propia de una extensión de la edad límite de la imputabilidad, donde el paradigma de lo exigible se mantiene situado en torno a las capacidades que son atribuidas al adulto ${ }^{15}$. Con ello, es claro que para este modelo, la adolescencia constituye una condición anormal, equivalente a la de quienes padecen de una especie de patología, motivando por ello (solo) la necesidad de considerar adaptaciones o adecuaciones a partir de las definiciones del régimen "normal"16. Además, y lo más importante, se pasa por alto el que conforme a dicha estructura la falta de satisfacción de dichas capacidades (mínimas) debiese traer aparejada la irresponsabilidad y no una extensión en las posibilidades de incriminación, aun y cuando se haga bajo un régimen de intervención atenuado, toda vez que ello supone aplicar el Derecho Penal sobre individuos que presentan caracteres que formalmente se reconocen como insuficientes para llegar a intervenir (no cuentan con la capacidad o condiciones mínimas requeridas) ${ }^{17}$.

\footnotetext{
${ }^{15}$ De ahí la distendida apreciación de una imputabilidad o culpabilidad disminuida en modelos que hoy en día extienden las esferas de la responsabilidad de adultos a los adolescentes. En Couso y Duce (2013), p. 317, se deja constancia de que la mejor defensa de este contenido la desarrolla FeLD en Estados Unidos, a efectos de justificar la prohibición de aplicar la pena de muerte o la prisión perpetua, propia del régimen de adultos, a los menores de edad.

${ }^{16}$ Con matices, en la propuesta de fundamentación de la especialidad sugerida por MAŃALICH RAFFO (2013), p. 220, quien asume una conclusión similar a partir de la asunción de la necesaria "heteronomía política" de los modelos dirigidos a adolescentes, a partir de la constatación de que no participan (formalmente) en su génesis, mediante el ejercicio del derecho a voto y derechos políticos en general.

${ }^{17}$ En este sentido se puede leer la interpretación propuesta por Mañalich RafFo (2013), p. 214, del texto del artículo 10 No 2 del Código Penal. En el mismo sentido Maldonado Fuentes, Francisco (2011). "Fundamentación y determinación de la pena en el Derecho Penal de adolescentes. A propósito del juicio seguido contra B. N. M. por delito de robo con intimidación (Ruc 0900505404-1) en la V Región”. Ius et Praxis, año 17, No 2, p. 525.
} 
Resulta, asimismo, doblemente contradictorio si tenemos en cuenta que el sustento de la intervención a partir de la afirmación de un menor grado de desarrollo supone una exigencia más elevada para la adolescencia en relación a la que justifica la responsabilidad de adultos, toda vez que el hecho de exigir responsabilidad bajo las condiciones propias de una menor capacidad conlleva la aplicación de un estándar limitativo menos riguroso que el previsto en el régimen general. Dicho en forma sencilla: lo que no alcanza para fundar la culpabilidad en el adulto es considerado suficiente para sostener dicha atribución en un adolescente, contraste que a todas luces deja en claro que ofrece un fundamento carente de sentido (que pareciera compensarse con una "rebaja" o "descuento" en la sanción). Incluso más, si se analiza desde un punto de vista preventivo el sustento de una capacidad de respuesta suficiente pero inferior a la "normal" no permite justificar la aplicación de una atenuación en la pena. Al contrario, habilita a sostener la necesidad de aplicar una intervención mayor, una que sea capaz de neutralizar dicho déficit en la capacidad de respuesta de los adolescentes. De esta forma, se trata de una perspectiva cuyos efectos concretos debieran motivar la aplicación de una respuesta proporcionalmente más invasiva o aflictiva en comparación con la de los adultos y no de una reacción atenuada como acá se propone.

Por otro lado, hay que tener en cuenta que dicho régimen supone estructurar los contenidos materiales del modelo en forma ilógica e inadecuada, en la medida en que ofrecen una modalidad de tratamiento que es virtualmente equivalente al que motiva la condición y posición social de los adultos en el ámbito de la responsabilidad penal. Como anticipamos, esta conceptualización lleva a sostener que las razones que justifican la intervención penal (delito y circunstancias relevantes) son siempre las mismas, sea que se trate de un adulto o de un menor de edad; que la forma de intervenir frente a ambos (es decir, que el contenido de las penas) también debe ser idéntica en ambos casos; $y$, sobre todo, que los objetivos perseguidos con su aplicación (finalidad de la pena) obedecen a las mismas orientaciones, aspectos, todos ellos, que ofrecen contenidos distintivos relevantes de considerar ${ }^{18}$.

$\mathrm{Al}$ respecto, debemos tener en cuenta que a estas alturas ya nadie pareciera discutir que el entramado de funciones y fines de la pena se presenta en forma diversa en adolescentes y adultos (especialmente sobre la base de la mayor consideración que se asigna a las finalidades preventivo-especiales) ${ }^{19}$, que la interacción del adolescente con el contenido de la norma penal se produce en forma particular (fundada en una aprehensión y asignación de sentido al significado que propone el injusto basada en la condición transitiva por la que atraviesa ${ }^{20}$ ) y, sobre todo, que la forma como se debe actuar sobre ellos debe incluir contenidos, modalidades y

\footnotetext{
${ }^{18} \mathrm{Vid}$. como ejemplo, las aplicaciones y diferencias extraídas de los caracteres propios de la adolescencia en Couso y Duce (2013), pp. 29 a 33 y 302 y ss. Asimismo, Von Hirsch (2012), pp. 67 y ss.

${ }^{19}$ Para una síntesis de los planteamientos vid. Couso y Duce (2013), pp. 376 y ss.

${ }^{20}$ Couso y Duce (2013), p. 311; Cruz Márquez (2012), pp. 17 y ss.; Von Hirsch (2012), pp. 67 y ss.
} 
características que carecen de sentido tratándose de un adulto. De esta forma, no es suficiente sostener que las capacidades del adolescente motivan la aplicación de una consecuencia (la misma) menos aflictiva que la aplicable a un adulto, sino de considerar que las diferencias presentes en ambos segmentos etarios, a partir de su caracterización natural, obliga a considerar que el adolescente interactúa en forma diversa con todas las instancias del sistema en la medida en que su condición lo hace procesar y reaccionar en forma diversa, tanto frente a la norma penal como respecto a la sanción penal. Con ello, la consideración de su estatus particular, en su real dimensión, lleva necesariamente a la valoración de necesidades preventivas diversas y a la aplicación de sanciones cuyo contenido también lo es, en la medida en que la caracterización particular del sujeto de referencia lleva a que en estos casos se persigan finalidades igualmente diferentes.

En este contexto, debemos tener en cuenta, además, que la aplicación de una pena menos rigurosa en el adolescente (lo que resulta plenamente razonable de sostener), emana de una consideración global de las características del menor de edad y no de un déficit en sus capacidades de reacción que incida negativamente en el merecimiento concreto que éste detenta respecto de la sanción. A este respecto, hay que tener en cuenta que la aflictividad de la pena produce efectos mayores a los que provoca en la población adulta y en un doble sentido ${ }^{21}$. Primero, pues la percepción de la restricción de derechos que ella impone es comparativamente más extensa en la medida en que la percepción del tiempo disminuye cuando envejecemos. Pero también -y lo más importante- pues conlleva un efecto desocializador mucho más riguroso, en cuanto la privación de derechos en la adolescencia incide en el ejercicio de su autonomía en un periodo en el que el individuo se encuentra precisamente aprendiendo a socializar, es decir, aprendiendo a ejercerla en correlación con los demás. La privación de su uso incide en una doble dimensión, pues retrasa dicho proceso personal (obligando a que tenga lugar en condiciones que impiden la administración de la autodeterminación), a la vez que lo priva de la posibilidad de adoptar las decisiones (normalmente determinantes) asociadas a dicho ejercicio, generando en definitiva un efecto en el presente y uno de futuro de consideración. En concreto, es claro que tres años de privación de libertad en un adulto constituyen una restricción importante de la libertad. En el adolescente, sin embargo, implican privarlo completamente de la posibilidad de vivir (toda) la adolescencia en condiciones de normalidad. De ahí que se aconseje una administración (penal) de la privación de libertad (y de las penas en general) comparativamente diferenciada a partir de supuestos connaturales a la adolescencia sin necesidad de llegar a considerarla como una anormalidad ${ }^{22}$.

\footnotetext{
${ }^{21}$ Couso y Duce (2013), p. 33; Von Hirsch (2012), pp. 72 y 73.
}

${ }^{22}$ De ahí que la Convención Internacional de Derechos del Niño (artículo 37 letra b)) destaque con especial énfasis el carácter de última ratio que debe inspirar el tratamiento de la privación de la libertad en el ámbito de la responsabilidad penal de los adolescentes. 
Debemos, además, tener en cuenta que el modelo en comento presenta un punto débil adicional, asociado a la incoherencia que conlleva el identificar una distinción sin extraer de ella las consecuencias que naturalmente ofrece. De hecho, la principal objeción formulada a este sistema apunta precisamente a lo difícil que resulta llegar a justificar una regla especial para los menores de edad con base en el desarrollo de sus premisas, en la medida en que la única posibilidad de interpretar coherentemente los presupuestos que le sirven de punto de partida lleva inevitablemente a la conclusión de que se debe postular la igualdad total entre adultos y adolescentes. En efecto, por las razones ya apuntadas, y a pesar de sus términos formales, la única forma de explicar coherentemente las bases propuestas es sostener que el estándar regular, normal o mínimo exigible se ha fijado en torno a la caracterización que ofrece la edad mínima considerada suficiente o capaz de responsabilidad, donde dicha regla no constituye una rebaja en las exigencias de la imputabilidad, sino, precisamente, la determinación de la propia regla general, mediante la cual se fija la capacidad mínima exigible. Basta para ello tener en cuenta que en estos modelos el estándar de contenidos que justifica la regla sobre la imputabilidad de los menores de edad -es decir, su inclusión en el sistema penal-, suele asociarse al hecho de que cuentan con plena capacidad de comprensión y volitiva para asimilar el sentido y alcance de la normativa penal, sin que pueda apreciarse una diferencia con aquél que suele dar forma a la regla general de la capacidad penal $^{23}$. Se trataría de una comprensión incompatible con la consideración de una regla de atenuación de pena especial fundada precisamente en su menor capacidad personal (aunque suficiente), aspecto que a pesar de ello pareciera ser igualmente característico en la construcción de estos modelos.

El problema radica en que el fundamento directo de dicha regla especial se asocia en estos casos a un ámbito (la capacidad para comprender el contenido de la ilicitud penal), donde las diferencias entre el adulto y el menor de edad no parecen relevantes. Con ello, se omite valorar en su conjunto la caracterización particular que detenta el adolescente, considerablemente más amplia, que su capacidad de percepción y control volitivo, y que tiene implicancias que superan con creces el campo de la imputabilidad y el reconocimiento que esta orientación le asigna en ella. De esta forma, lo que sucede es que el presupuesto aludido (acertado de apreciar) es tratado en forma incompleta, arribando a resultados y efectos que no son acordes a su condición. Por lo que estos modelos no logran explicar el contenido que permite diferenciar dos rangos de capacidad (el del adolescente y el del adulto), ni menos aún les permiten justificar la regla de atenuación que de ello se extrae.

No obstante, debemos tener en cuenta que hay otros componentes de este modelo que parecieran poner en evidencia por qué se intuye que el adolescente

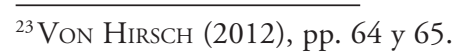


(y el menor de edad, en general), presenta una caracterización personal global bastante distinta a la del adulto ${ }^{24}$. Al respecto, hay que tener en cuenta que en la administración de estos modelos se tuvo siempre en consideración el que resulta imposible establecer a priori una regla general y absoluta que determinara (positivamente) la capacidad penal del menor de edad, rechazándose con ello, en general, la utilización de criterios cronológicos para la determinación de imputabilidad. En su lugar, se prefirió siempre establecer mecanismos que permitieran una evaluación particular, es decir, una que determinara la capacidad de culpabilidad en cada caso concreto. La mayoría de los modelos optó por establecer un rango inferior donde se presume la incapacidad, un rango superior asociado a la mayoría de edad y un periodo intermedio donde se debía proceder a dicha valoración particular (si era capaz de discernir), buscando de esta forma afirmar si podía efectivamente comprender el sentido y alcances de la ilicitud y contaba con el control volitivo suficiente para adoptar decisiones al respecto ${ }^{25}$. De hecho, esta dinámica es tan característica en estas aproximaciones que se suele individualizar a los sistemas clásicos como modelos del discernimiento.

Si bien el objeto de referencia para dicha resolución no ofrece contenidos diversos a los que se exigen en la acreditación de la capacidad del adulto el solo hecho de reconocer tras la consagración del discernimiento que la diversidad en el desarrollo (esencialmente gradual) que experimenta el individuo durante la adolescencia constituye una característica definitoria de dicha etapa, conlleva el reconocimiento de un componente personal propio y particular, en algo que va mucho más allá del ámbito de las capacidades a las que se refiere la imputabilidad ${ }^{26}$. Y es que el adolescente vive una etapa en la que naturalmente está llamado a experimentar los desafíos propios de la adaptación a la vida independiente y la configuración y decisión de los aspectos esenciales que determinarán su personalidad, procesos (ambos) que motivan una

\footnotetext{
${ }^{24} \mathrm{~A}$ este respecto hay que tener en cuenta que la sociedad del siglo XIX no conoció (ni reconoció) formalmente tras la adolescencia un segmento especial y autónomo que permitiera caracterizar el desarrollo evolutivo de los individuos en dicha etapa en forma particular. En síntesis, las relaciones sociales se configuran para el derecho en dicha época, diferenciando a personas capaces y a incapaces por razones de edad, pasando los infantes a la edad adulta en forma directa.

${ }^{25} \mathrm{~A}$ todo ello debemos agregar que la práctica demostró que dicho objetivo es imposible de medir, siendo en general sustituido por una valoración de las condiciones personales asociadas a necesidad preventiva especial de pena. Al respecto VIVES ANTÓN, sentencia categóricamente: "Si hay algo filosóficamente pacífico en nuestro tiempo es la idea de que ese presupuesto (culpabilidad) no puede demostrarse ni en general, ni, menos aún, en un caso concreto", en VIVEs AnTón, Tomás Salvador (1995). "Constitución y Derecho Penal de Menores". En: La Libertad como Pretexto, Valencia: Tirant lo Blanch, p. 351. En el mismo sentido se manifiesta SiLVA SÁnchez (1997), p. 183, quien en relación al discernimiento señala: "sobre cuya dificultad de comprobación caso por caso no es necesario insistir". Por su parte CILleRo BRUÑol afirma: "Desde un punto de vista empírico el discernimiento en sentido clásico resulta ser una cualidad difusa de imposible determinación, que se presta para interpretaciones subjetivas del juzgador o de los peritos que apoyan su decisión". Vid. Cillero Bruñol, Miguel (2002). "Artículo 10 No 2 y 3". En: Texto y Comentarios del Código Penal Chileno, Politoff, Sergio y Ortiz, Luis (Dirs.), Matus, Jean Pierre (Coord.), Tomo I, Libro Primero, Parte General, Santiago: Editorial Jurídica de Chile, p. 123.

${ }^{26}$ Dicha diversidad se reconoce explícitamente en VON HIRSCH (2012), p. 68.
} 
caracterización de su comportamiento particular y lo colocan como un referente diverso frente a los objetivos y formas de actuar del sistema (de control) penal. Sus experiencias vitales también vienen condicionadas por componentes ambientales (familiares y sociales) que inciden de manera determinante en la velocidad e intensidad con que se vive el paso a la autogestión de la responsabilidad ${ }^{27}$.

Así como en términos físicos se trata de individuos que deben aprender a operar con una estructura corporal que se modifica en forma progresiva y vertiginosa (lo que motiva numerosos actos de torpeza que son asumidos, en general, como "propios de la edad"), el adolescente debe igualmente aprender a convivir con una estructura de personalidad que se modifica en términos similares. Sus capacidades lo enfrentan, por primera vez en la vida, a la toma de decisiones trascendentales que generan efectos permanentes en su desarrollo futuro, para lo cual ya no cuenta con el soporte que le brinda la cómoda posición que es propia de la infancia, donde las decisiones personales trascendentes se confían a la voluntad de terceros. Dichas exigencias pasan en este periodo por las etapas propias de la iniciación, la necesidad de sometimiento a prueba, de ensayo acerca de los límites de la autonomía y, consecuentemente, de experimentación, de una profunda necesidad de reafirmación por parte de terceros y de apoyo en las masas o grupos de pares (propio de la inseguridad en la actuación individual). Dicho proceso se vive, además, en condiciones muy desiguales, ampliamente variables y sujetas a una rápida evolución, siendo destacable el grado de cambios posibles de percibir en su desarrollo evolutivo en breves periodos de tiempo.

La personalidad adolescente no es por ello sólo una etapa previa a la obtención de la autonomía individual y tampoco es el fruto o consecuencia de un proceso de desarrollo personal: es más bien la etapa en la que se produce dicha mutación y que se extiende hasta su término ${ }^{28}$. De ahí que se suela caracterizar este proceso personal como el propio de un desarrollo progresivo, donde lo relevante apunta a entender que el adolescente se encuentra sometido a dicha variabilidad en su estructura de personalidad, lo que afecta e incide en su capacidad de interacción con los demás y, particularmente, en la que es capaz de desarrollar respecto de las estructuras institucionales en las que se inserta el sistema penal.

Todo ello hace que el delito cometido por un adolescente pueda ofrecer una amplia diversidad de sentidos y encontrar su explicación en un sinnúmero de causas diferentes ${ }^{29}$, lo que incrementa la necesidad de ponderar de manera más amplia los diversos elementos de juicio concomitantes al hecho y circundantes al

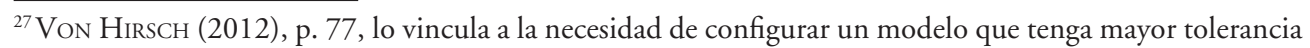
frente al fracaso de dicha administración individual.

${ }^{28}$ CRUZ MárQuez (2012), p. 15.

${ }^{29}$ Hernández Basualto (2007), pp. 202 y ss.; Horvitz Lennon, María Inés (2006). "Determinación de las sanciones en la ley de responsabilidad penal juvenil y procedimiento aplicable". Revista Estudios de la Justicia, No 7, pp. 98-99; MALdONAdo Fuentes (2009), pp. 8 y ss.
} 
infractor ${ }^{30}$, considerar una valoración diversa de las necesidades preventivas que cumple el sistema penal; orientar un diverso campo de objetivos posibles de alcanzar mediante su utilización y definir una modalidad distinta de actuación para obtenerlos. Todo ello lleva, sin duda, a una caracterización mucho más amplia que la que emana de la sola consideración de una diversa capacidad de culpabilidad.

Son por ello diversos los delitos que ameritan atención de parte del modelo y los elementos de juicio que deben ser tenidos en cuenta para configurarlos; diversos los contenidos de la sanción penal prevista para reaccionar frente a aquellos (y más amplio el abanico de alternativas de solución diversas a la que ofrece una condena); finalmente son también diversos los fines perseguidos con su imposición, siendo igualmente diferentes las formas como el órgano jurisdiccional debe aproximarse a su valoración, en cuanto parece indispensable que cuente con un mayor grado de discrecionalidad en dicha tarea (para dar cuenta de su amplia variabilidad).

Esto último es precisamente lo que se intuye tras la consideración del discernimiento como instancia esencial para la valoración de la capacidad del adolescente, tras lo cual se evidencia la consideración de un aspecto distintivo y característico de su propia personalidad.

\subsubsection{Sintesis}

El modelo clásico nos ofrece, entonces, la necesidad de rescatar la autonomía posible de afirmar tras el comportamiento del adolescente, como también la necesidad de valorar las particularidades que emanan de los caracteres naturales que ofrece su personalidad. Asimismo, deja en claro que las dimensiones que ofrece este contenido distintivo se extienden a todos los ámbitos definitorios del modelo de intervención penal, superando con creces la sola aplicación de sus efectos en el ámbito de la imputabilidad penal y sus consecuencias en la pena aplicable.

De esta forma, las limitaciones que a este respecto evidencia el modelo lleva a considerar que los contenidos que emanan de estas exigencias no fueron apreciados bajo sus caracteres con la precisión o profundidad requeridas. En concreto, si bien parece acertada la afirmación de una capacidad de culpabilidad diferente en los menores de edad, la consecuencia de dicha premisa no se traduce en una reducción del margen de aflictividad cuantitativa de la sanción de adultos. Tampoco parece acertado limitar su afirmación a la constatación de un proceso de maduración in-

\footnotetext{
${ }^{30}$ Cruz Márquez (2012), pp. 17 y ss. Couso y Duce (2013), pp. 311 y ss. Se agregan además otras razones en Cillero Bruñol, Miguel (2008). "Consideraciones para la aplicación del criterio de idoneidad en la determinación de las sanciones en el Derecho Penal de adolescentes chileno”. Documento de Trabajo No 13, Unidad de Defensa Penal Juvenil, Defensoría Penal Pública. Posteriormente publicado en una versión corregida bajo el título "Proporcionalidad y fines de la sanción penal de adolescentes: consideraciones para la aplicación del criterio de idoneidad de la sanción”. En: Estudios de Derecho Penal Juvenil I, Centro de Documentación de la Defensoría Penal Pública, serie Informes en Derecho No 5, noviembre 2009, pp. 137-171.
} 
dividual diferenciado que fundamente una menor exigibilidad, pues de lo que se trata es de verificar que la condición social que es reconocida al adolescente tiene un impacto en todo el proceso de atribución de la responsabilidad penal. Limitar a dichos componentes los contenidos de especialidad del modelo, constituye por ello tratamiento parcial de los propios presupuestos que le sirven de base a esta orientación, que por ello no da cuenta de los requerimientos que supone la consideración de su personalidad natural y la incidencia que ella ofrece en la operatoria del sistema penal. Así, por ejemplo, constituiría un razonamiento inapropiado (en sede de individualización de la pena, conforme a lo previsto en el artículo 24 de la Ley No 20.084) el sostener que la "menor culpabilidad" del adolescente se traduce en exclusiva en una menor extensión de la sanción, pudiendo incidir, conforme a sus caracteres particulares, en su caracterización cualitativa. También lo sería el sostener que su (elevada) capacidad de comprensión del contenido de ilicitud del hecho atribuido permite establecer paralelos con los efectos previstos en el régimen penal general (de adultos), en cuanto ambos individuos detentan una condición diversa desde el punto de vista de la exigibilidad. La pena es, y debe ser, respecto a adolescentes, cualitativamente diversa (aun y cuando se haya superado la barrera de la mayoría de edad durante la ejecución). Por lo mismo, tampoco parece propio asumir que la capacidad de reacción y responsabilidad que se les exige es la propia de un adulto, si bien reducida, como la afirmación, sobre dicha base, de definiciones (referidas a fines, formas de reacción o justificación de sanciones) que razonan a partir de las capacidades sociales de la población adulta. Finalmente, tampoco parece acertado asumir como premisa que los contenidos de injusto previstos como delito en la ley penal se dirigen de manera indiferenciada a los individuos menores de edad, radicando la totalidad de las razones de su eventual inaplicabilidad a dicha franja etárea en cuestiones asociadas a su imputabilidad. Se trata de asumir que la comisión de ciertos delitos, durante la adolescencia, ofrece un significado diverso como hecho social, lo que solo se puede sostener a partir de la constatación de las condiciones personales diversas que naturalmente ofrece la adolescencia.

Debió pasar casi un siglo para que los aspectos asentados por esta doctrina que resultan valorables y necesarios de considerar fueran recogidos en la configuración de los sistemas penales dirigidos al tratamiento de los adolescentes. En medio, el desarrollo que sucede a la época clásica tendió más bien a profundizar en los caracteres particulares que ofrece la personalidad del adolescente, en un esquema que llevó a entenderlos o procesarlos como un motivo para sostener su incapacidad, con consecuencias que no pueden ser valoradas en forma positiva.

\subsection{Modelo tutelar (doctrina de la situación irregular)}

\subsubsection{Descripción}

En las antípodas del modelo recién descrito se ubica el denominado sistema tutelar o proteccional que precisamente sucede al sistema clásico en términos his- 
tóricos. Sus premisas pivotan sobre la idea de que los menores de edad no gozan en la sociedad contemporánea del reconocimiento de capacidades individuales y autónomas que permitan atribuirle consecuencias a sus actos, debiendo el sistema operar, en consecuencia, a partir de su irresponsabilidad.

Si bien dicha base debiera llevar a la inhabilitación de los sistemas penales para reaccionar frente al delito cometido por menores de edad (lo que constituyó parte de sus objetivos declarados), las raíces positivistas que dan forma al modelo hacen que dicha virtual incapacitación sea más bien valorada como una condición que igualmente demanda una reacción estatal, en la medida en que el delito pasa a ser considerado como un déficit de socialidad o un síntoma del mismo, a la vez que un infortunio que emana de las condiciones (preferentemente sociales) que padece el menor de edad. Se trataría de una expresión de la situación (social) irregular por la que atraviesa el menor de edad.

En efecto, se asume que el delito de un adolescente (o de cualquier menor de edad) no es sino el reflejo de una condición de carencia que afecta su socialidad, cuyos orígenes son identificados en torno a los caracteres de su situación personal familiar y posibilidades sociales de desarrollo individual. Las malas condiciones sociales pasan por ello a ser concebidas como un factor criminógeno cuyos efectos son sufridos por el adolescente en forma determinante. De ahí que el Estado deba actuar sobre ellos, en su propio beneficio y, en particular, para protegerlo de su padecimiento en atención a que su incapacidad le impide enfrentarlos de manera autónoma en forma adecuada. Su situación irregular, que en este caso, se expresa en el delito, debe por ello ser neutralizada por el Estado en base a la aplicación de medidas que integren su política social, carentes por ello del contenido y significado (estigmatizante) que es propio de toda sanción penal.

Bajo este esquema, la infracción penal de adolescentes no lleva a la imposición de una pena, sino de una medida proteccional; el conocimiento del caso se administra por un órgano especializado en problemas de infancia (Tribunal de Menores) y no por un juez penal, donde se analizan y resuelven todos los casos asociados a la problemática social de los menores de edad. Dicho tribunal resuelve en base a un procedimiento en el que no son relevantes las garantías individuales, en cuanto el conocimiento judicial se orienta a una intervención que es definida como beneficiosa para el propio menor; el objeto del conocimiento judicial no está centrado en el delito (que perfectamente puede ser valorado como un signo casi irrelevante) sino en la condición de marginalidad que se entiende que lo motiva. El tratamiento es equivalente (en naturaleza y objetivos), al que recibe un menor de edad que no ha delinquido pero que padece de una situación de carencia personal (por ejemplo, de abandono). Finalmente, la naturaleza y extensión de la intervención estatal se vincula a la condición psicosocial del afectado, con un enfoque que se configura en términos preventivo-especiales.

Podrá apreciarse que dicha dinámica de intervención excede el campo de lo que tradicionalmente se asocia al Derecho Penal en cuanto el presupuesto propio para la 
actuación tutelar o proteccional abarca supuestos más amplios que los que concede la comisión de un delito. No obstante, lo relevante es que precisamente los casos en que dicho hito motiva la necesidad de intervención estatal la vía escogida sea precisamente la proteccional, sustrayendo de esta forma el tratamiento criminalizante (al menos a nivel formal) por uno diverso, bajo el amparo que concede la afirmación de la incapacidad de los menores de edad. De hecho, se considera casi como una muestra de "barbarie" el que se hayan impuesto en épocas previas sanciones penales a "incapaces" como los menores de edad, patentándose el movimiento y sus adeptos como "los salvadores del niño", en tanto proponen su sustracción de los espacios de aplicación de la pena criminal. Se singulariza el proceso como exitoso bajo la idea de que "el menor habia salido del Derecho Penal", lo que constituiría, bajo dicha perspectiva, un logro humanitario. De esta forma, el Estado ya no va a reaccionar frente al delito, sino que lo va a hacer con una herramienta diversa, centrada en la problemática social que afecta y aqueja al menor de edad, actuación que de esta forma es configurada como un beneficio. Dicho sea de paso, resulta relevante tener en cuenta que dichas herramientas también consideran la posibilidad de imponer restricciones al ejercicio de derechos fundamentales, incluyendo la privación de la libertad, operando en términos que se asocian estrictamente al ideario de la prevención especial positiva (resocializadora).

La conceptualización del conflicto penal cometido por adolescentes bajo la óptica tutelar dominó el tratamiento político criminal en el mundo occidental durante gran parte del siglo XX, constituyendo una de las ideologías que más éxito ha suscitado en el ámbito de las políticas públicas asociadas al control penal. Sobre estas bases, a partir de 1899 (fecha en que se crea el primer Tribunal tutelar de Menores en Chicago), el sistema de control penal formal aplicable a los adolescentes en razón a la comisión de un hecho constitutivo de delito es sustituido paulatinamente, en todo el mundo occidental, por un sistema -igualmente de control- de naturaleza tutelar ${ }^{31}$, como puede comprobarse en nuestros Códigos hispanoamericanos recientes (y, en su mayoría, aún vigentes) ${ }^{32}$.

\subsubsection{Valoración}

El modelo tutelar introduce una cuota importante de sensibilidad en la valoración de la problemática que encierra la comisión de un delito por parte de un menor de edad. En efecto, se trata de una aproximación que pone de relieve el que la rudeza del castigo penal se torna mucho más gravosa en dichos casos, rescatando

\footnotetext{
${ }^{31}$ Vid. SÁnchez García de Paz, Isabel (1998). Minoría de edad penal y Derecho Penal juvenil. Granada: Comares, Granada, pp. 97 y ss.

${ }^{32}$ Para una síntesis reciente García Méndez, Emilio (2004). Infancia. De los derechos y de la justicia. Buenos Aires: Editores del Puerto, 2a edición actualizada, pp. 15 y ss.
} 
además la influencia que pueden llegar a ejercer las condicionantes sociales, familiares y de desarrollo personal en la capacidad de desempeño social del adolescente y, con ello, en su culpabilidad, ofreciendo una perspectiva que a todas luces presume de brindarle un tratamiento más humanitario. No obstante, estas consideraciones llevan a la configuración de un modelo en el que dichos contenidos sirven de base para la aplicación de intervenciones ampliamente discrecionales, más invasivas y aflictivas, de carácter indeterminado, impuestas en condiciones desiguales y ajenas a los controles propios que exige el Estado de Derecho, configurando un estatuto mucho más gravoso al que caracteriza al Derecho Penal tradicional.

Hay que tener presente que se trata de una corriente que opera en base a premisas análogas a las que inspiraron a la escuela positiva italiana y al correccionalismo, en las que, igualmente, se llega al extremo de sostener la necesidad de que el Derecho Penal sea sustituido por un sistema de medidas orientadas a la resocialización del individuo fundadas en la sola afirmación de su peligrosidad social (y criminal), por razones (utilitaristas) asociadas a necesidades preventivas (de control del delito) y con base en el supuesto beneficio que ello produce para la vida futura de quien debe padecerlas (paternalismo).

Con ello, parece claro que concurren a este respecto las mismas razones que en su tiempo llevaron al fracaso a la pretensión de sustituir al sistema penal por un modelo similar al enunciado, y que casi inexplicablemente, lograron un rotundo éxito en este ámbito. En definitiva, y como sostiene GiménEz Salinas, "no es que el menor saliera del Derecho Penal, puesto que se le seguian aplicando medidas sancionadoras, sino que lo que sucedió es que salió del sistema de garantías y derechos individuales" ${ }^{33}$. Problemas de proporcionalidad, legalidad, indeterminación, arbitrariedad, intervención coactiva con base al carácter, forma de ser o condición social (Derecho Penal de autor), entre otras cuestiones críticas dan forma a un régimen que inexplicablemente se mantuvo vigente a pesar de la vigencia permanente de los regímenes constitucionales correspondientes (y las garantías que ello supone). En efecto, las consecuencias previstas en este modelo presentan un contenido restrictivo de los derechos individuales análogo al que configura una sanción penal, con el agravante de que se integran además por acciones ejecutivas orientadas a incidir en las condiciones personales del adolescente que son interpretadas como un déficit en su adaptación social. Se imponen al margen de los límites asociados al Derecho Penal de culpabilidad, actuando a partir de supuestos no atribuibles (la peligrosidad); sin necesidad de acreditación o consideración del comportamiento desplegado (principio del hecho o de culpabilidad por el hecho); sin límites temporales ajenos a la necesidad preventiva (medidas indeterminadas); y con total independencia al contenido de autonomía que materialmente es posible identificar

${ }^{33}$ Vid. Giménez-Salinas I Colomer, Esther (1993). "La mayoría de edad penal en la reforma”. En: Homenaje a Juan del Rosal, Madrid: Editoriales de Derecho Reunidas, p. 611. 
(y que se debe reconocer) en todo individuo. Finalmente, se busca incidir sobre el individuo sobre la base de intervenciones proactivas destinadas a modificar su personalidad (prevención especial positiva).

En este contexto, la privación de libertad (por ejemplo) es presentada como una herramienta que busca apartar al adolescente de un entorno que lo llevó a delinquir, ofreciéndole en su reemplazo un contexto apto para su configuración como individuo útil a la sociedad (lógica correccional). El objetivo es actuar para corregir y educar al individuo, obviando el que la privación de libertad también resulta efectiva para superar la condición de riesgo que se supone y presume existente respecto del resto de los integrantes de la sociedad ${ }^{34}$.

En efecto, se omite (intencionalmente) que a través de estas medidas la sociedad se defiende preventivamente de la infancia peligrosa, incapaz de enfrentar y superar la problemática de marginalidad social que la afecta, y que la transforma en potencial elemento antisocial ${ }^{35}$, contenido inevitablemente asociado a la base de defensa social cofundante de la propuesta.

Ello impide aceptar la idea de que la intervención resocializadora se legitime por el solo hecho de que es interpretada como una intervención positiva, cuyo fin apunta a favor del propio afectado, aspecto sobre el que se deposita la base de legitimidad del modelo. De esta forma, tampoco resulta posible aceptar que las garantías procesales propias del proceso penal deban ser entendidas en este contexto como restricciones innecesarias, en la medida en que el objetivo de la intervención no es percibido (y configurado) como un mal para el infractor o el que carezca de sentido por ello limitar las posibilidades de actuación de una intervención que mira (supuestamente) en su propio y exclusivo beneficio.

Todo ello, finalmente, se apoya además en un supuesto falaz: el desconocimiento de las capacidades reales de autodeterminación de que gozan (naturalmente) los adolescentes (y en alguna medida los menores de edad en general), argumento que de forma cómoda parece dar sentido y justificar el contenido paternalista que se propone como base para justificar estas modalidades de intervención. En efecto, la incapacitación atribuida a las facultades del menor de edad opera en estos casos como una excusa, que no priva al adolescente de los efectos coactivos y restrictivos de derechos que caracterizan a la actuación estatal dispuesta para hacer frente a su comportamiento, sino que permite administrarlos bajo condiciones considerablemente menos exigentes a las que rigen el sistema de control penal formal. Se trata por ello de un mecanismo de legitimación tautológico y circular que, a

\footnotetext{
${ }^{34}$ Vid. García Méndez, Emilio (1997) Derecho de la Infancia-Adolescencia en América Latina. De la situación irregular a la protección integral. Tolima: Forum-Pacis, 2a edición, pp. 43, 44 y 47.

${ }^{35}$ Por ello resulta errónea la afirmación de Vives AnTón (1995), p. 351, en el sentido de entender que "durante más de medio siglo hemos podido vivir sin aplicar penas a los menores de dieciséis años", la que incluso resulta contradicha por su propio texto (en p. 349) al denunciar el histórico fraude de etiquetas del modelo tutelar.
} 
fin de cuentas, pretende justificar la negación actual de la libertad en aras de su (supuesta) obtención futura ${ }^{36}$.

La idea de que la incapacidad de los menores de edad no constituye una excusa suficiente para sobrepasar los límites del debido proceso, ni las garantías características de los sistemas penales (en ese orden) se transformó en una constante en los Estados Unidos a partir de la resolución recaída en el conocido caso "In Re Gault" (387 U.S. 1, 27, 1967). En dicha oportunidad la Corte Suprema de Estados Unidos de América sostuvo, contundentemente, que la privación de libertad (de un menor de edad) motivada en la comisión de un delito no puede ser sometida a un régimen de garantías diverso al de un adulto en análoga situación, más allá y con total independencia que se encuentre orientada a su tratamiento, rehabilitación o que a partir de ello se sustente el que mira a su propio beneficio ${ }^{37}$. Con ello, plasmó un precedente pionero en el asentamiento de esta cuestión, hoy en día indiscutida. Por su parte, y dentro de nuestro entorno cultural (específicamente en lo referido a la normativa penal) es similar la experiencia que lleva a España a adoptar -tras largos años de debate y discusión- un modelo de justicia penal especializada dirigido a adolescentes, exigido a través de la Sentencia 36/1991 del TC. Dicha resolución motivó la necesidad de introducir con urgencia una modificación a la regulación positiva (LO 4/1992) que permitiera conservar una instancia de control bajo las exigencias (mínimas en dicho caso) del régimen constitucional, que posteriormente desencadena el establecimiento de un régimen especial de responsabilidad del menor que considera las garantías propias de un caso penal ${ }^{38}$.

En concreto y más allá que ambas resoluciones radicaron sus efectos en la operatoria procedimental proponen en la base un criterio de carácter general, evidente en el caso americano (por su propia configuración como sistema) y que se expresa en el caso español en los efectos que motivó su dictación, constituyendo el detonante concreto que motiva -en definitiva- la LO 5/2000 sobre responsabilidad del menor.

\subsubsection{Sintesis}

Los modelos tutelares han evidenciado sus déficits de legitimación, con particular nitidez a partir de la década de los ' $80^{39}$. De ahí que los diversos sistemas

\footnotetext{
${ }^{36}$ Por todos De Figueiredo Dias, Jorge (2004). Direito Penal. Parte Geral. Lisboa: Coimbra Editora, p. 94.

${ }^{37} \mathrm{Al}$ respecto vid. Fletcher, George (1997). Problemas básicos del Derecho Penal. Valencia: Tirant lo Blanch, pp. 51-2; Zaffaroni, Eugenio Raúl (2002). Derecho Penal. Parte General. Buenos Aires: Ediar, 2a edición, p. 187.

${ }^{38} \mathrm{Al}$ respecto vid. Cervelló Donderis, Vicenta y ColÁs Turégano, Asunción (2002). La responsabilidad penal del menor de edad. Madrid: Tecnos, pp. 103 y ss.; Ornosa Fernández, María Rosario (2003). Derecho Penal de Menores. Comentarios a la Ley Orgánica 5/2000, de 12 de enero, Reguladora de la Responsabilidad Penal de los Menores. Barcelona: Bosch, 2a edición, pp. 33-4.

${ }^{39}$ Hoy es claro que como sujeto de derechos el adolescente es titular de manera autónoma de los derechos que son comunes a toda persona humana, asumiendo adicionalmente la titularidad de aquellos que le asisten
} 
jurídicos hayan previsto la necesidad de introducir modificaciones profundas a las modalidades de tratamiento de los conflictos penales de adolescentes. Con ello, la experiencia que deja la implementación de estos modelos ofrece una serie de efectos (no necesariamente positivos) y excesos útiles de tener en cuenta a la hora de asumir dicha tarea. Entre ellos destaca, en primer lugar, el que reafirma la necesidad de reconocer y respetar la autonomía de que gozan los adolescentes, tanto en los contenidos que dicho presupuesto aporta de cara a la fundamentación de la intervención como en los límites que conlleva para dicha actuación ${ }^{40}$. Pero además de dichos aspectos normativos se trata de un supuesto que contribuye sensiblemente a nutrir al sistema de mayores expectativas de efectividad, pues la óptica de la irresponsabilidad y la discrecionalidad generan mensajes contraproducentes para los objetivos referidos a la prevención. A la imagen de impunidad se agrega la sensación de que no hay nada que el adolescente pueda hacer para evitar la intervención, lo que minimiza el tratamiento y esfuerzo que éste debe asignar a su propia inhibición, con efectos que evidentemente inciden en su comportamiento futuro.

Conviene además destacar, en segundo lugar, que estas experiencias dan cuenta de los riesgos asociados a la pretensión de centrar las bases del sistema en el tratamiento educativo o resocializador (preventivo especial), en la medida en que su consideración preferente o exclusiva lleva necesariamente a excesos y a la instrumentalización ${ }^{41}$. Su tratamiento debe adaptarse a exigencias adicionales que precisamente emanan del reconocimiento de la autonomía del individuo. Por ello, no resulta posible tolerar decisiones ni argumentos basados en la exclusiva pretensión de reinserción o resocialización del condenado (sin consideración a la autonomía que naturalmente se les debe reconocer), ni tampoco aquellas que se basan en una definición de dichos contenidos a partir de la sola experiencia u opinión personal de quien resuelve (debiendo, por contra, basarse en una perspectiva de derechos), ni menos aun la imposición de reacciones indeterminadas (en duración o contenidos). Finalmente, y por las mismas razones, tampoco resulta tolerable exceder los límites que impone la culpabilidad a partir de objetivos de reinserción social,

\footnotetext{
en su condición de menor de edad. No se puede actuar en interés del menor, restringiendo sus derechos y reconocerle con ello al mismo tiempo el carácter de sujeto y titular de los mismos siendo necesario recordar que la experiencia histórica da cuenta de una "tendencia generalizada a desconocer los derechos del niño como un limite (constituyendo) una orientación a las actuaciones de las autoridades y los adultos en general', CILLERO BruÑol, Miguel (1999). "El Interés Superior del Niño en el marco de la Convención Internacional sobre los Derechos del Niño”. En: Infancia Ley y Democracia en América Latina, García Méndez, Emilio y Beloff, Mary (Comps.), Buenos Aires: Temis-Depalma, p. 80.

${ }^{40}$ Ahí radica a nuestro juicio una de las diferencias determinantes con los planteamientos que de forma mayoritaria asimilan la persecución de objetivos preventivo generales y retributivos o de merecimiento. $\mathrm{Al}$ respecto vid. Couso y DuCE (2013), pp. 376 y ss. Asimismo, respecto de los contenidos y expectativas cualitativas de la intervención (sobre el desarrollo de la autonomía moral del adolescente), pp. 392 y 393.

${ }^{41}$ Hoy se sostiene, de forma absoluta, que los objetivos preventivo especiales en modo alguno permitan justificar intervenciones más allá del límite que ofrecen las exigencias preventivo generales, retributivas o centradas en las condiciones de merecimiento personal de la sanción. Vid. Couso y DuCE (2013), pp. 376 y ss.
} 
ni someter a revisión los contenidos de la sanción a partir de la adhesión interna que el adolescente demuestre respecto de los valores que se pretenden transmitir.

\subsection{Modelo educativo}

\subsubsection{Descripción}

El denominado modelo educativo -también conocido como modelo del bienestar (welfare model) - propone una especie de mixtura en el tratamiento asignado a los conflictos penales en que incurren los menores de edad. Por un lado, se asume la plena aplicabilidad del sistema penal en una modalidad atenuada, equivalente en su base a las características propuestas por el liberalismo clásico, con las adaptaciones correspondientes al desarrollo que adquiere la ejecución penal durante la primera mitad del siglo XX. Ello implica, básicamente, la incorporación de la orientación y contenidos preventivo-especiales en la operatoria del sistema, especialmente, en la definición progresiva del régimen de ejecución penal, en las modalidades que caracterizan al tratamiento en la administración de la privación de libertad y en la consideración de sustitutivos penales, que son incorporados a fin de evitar los efectos desocializadores de la pena.

Dicha dinámica se complementa con una profundización y ampliación de las alternativas ofrecidas por el modelo, para evitar el tratamiento del caso sobre la base de las consecuencias del sistema penal formal. Concretamente, se materializa a través de una oferta de programas de carácter administrativo, de orientación frontalmente socioeducativa, que apuntan a lograr la adhesión voluntaria y compromiso del infractor, dejando en evidencia que, al igual que en el modelo tutelar, se busca sustraer al menor de edad de los efectos y significados del rigor penal.

Como propuestas características destaca la implementación de programas o planes de diversión (entendida como prescindencia o sustracción a procedimientos formales de solución) ${ }^{42}$, que adoptan la forma de una libertad controlada (que puede llegar a considerar el control, la reclusión parcial o domiciliaria) o de mediación-reparación o conciliación ${ }^{43}$. Por ambas vías se busca favorecer una respuesta administrativa basada en un modelo de intervención cuyos objetivos apuntan a incidir en la formación personal del adolescente (en el más amplio sentido) para procurar su adhesión a (o simplemente su convencimiento de la conveniencia de acatar) parámetros de relación interpersonal que sean respetuosos de los derechos de terceros. Se parte de la afirmación -y reconocimiento- de la responsabilidad

\footnotetext{
${ }^{42}$ Vid. DƯNKEL, Frieder (2001). "Reacciones en los campos de la administración de justicia y de la pedagogía social a la delincuencia infantil y juvenil: Un estudio comparativo a escala europea". En: La responsabilidad penal de los menores: Aspectos sustantivos y procesales", Ornosa Fernández, María del Rosario (Dir.), Cuadernos de Derecho Judicial, No III, p. 129.

${ }^{43}$ Idem.
} 
para trabajar el concepto de formación en sociedad ${ }^{44}$, ocupando asimismo dinámicas asociadas al reconocimiento, identificación y toma de conciencia del daño, con la misma finalidad.

Las metodologías, modelos de intervención o dinámicas de tratamiento son de tipo terapéutico, de seguimiento y control, de apoyo y acogimiento familiar, de resarcimiento del daño causado a la víctima -ya sea en su favor directo o simbólicamente- u otros planes y actividades de similares características, de cuyo cumplimiento satisfactorio depende en general la suspensión del procedimiento, y naturalmente la evitación de la eventual condena.

Se conceden sobre esta base amplias facultades a la judicatura para favorecer e incentivar la "opción" del menor de edad por la vía educativa (administrativa) y conciliatoria, considerando el apoyo (a veces determinante) de instancias técnicas especializadas en el ámbito de las ciencias psicosociales. Las decisiones a este respecto suelen basarse en pronósticos asociados a la "recuperabilidad" (en un sentido similar a la resocialización) del infractor, cuya caracterización determina el curso de acción a seguir y, en su caso, la medida que parece adecuada de proponer (o imponer); su cese, basado en condiciones que permitan sostener que su cumplimiento es ya innecesario; $y$, en su caso, el cierre definitivo del proceso de instrucción formal del sistema penal.

La implantación de sistemas basados en este modelo se desarrolla desde mediados del siglo XX principalmente en Estados que se organizan bajo el paradigma del estado social o que cuentan con una mayor disponibilidad económica en el presupuesto público destinado a prestaciones de carácter social. Ello explica por qué los ejemplos suelen situarse en torno a países que forman parte del mundo desarrollado europeo y del norte del continente americano ${ }^{45}$.

\subsubsection{Valoración critica}

El modelo descrito ofrece la ventaja de desarrollar contenidos que hasta la fecha parecían opuestos a través de una fórmula en las que logra integrarlos de manera sistemática, procurando con ello el aprovechamiento de sus aspectos positivos. Así, por ejemplo, deja en evidencia que el paso del menor de edad por el sistema judicial no parece algo deseable, sin llegar por ello a negar que se trate de conflictos de carácter penal, ni el que las respuestas procedentes tengan dicha connotación.

\footnotetext{
${ }^{44}$ Sobre este concepto, descrito en términos amplios, esto es, desarrollados sin asociación específica a medidas propias de los modelos calificados como educativos, vid. Gomes DA Costa, Antônio Carlos (1997). "Pedagogía y justicia". En: Infancia Ley y Democracia en América Latina, García Méndez, Emilio y Beloff, Mary (Comps.), Buenos Aires: Temis-Depalma.

${ }^{45}$ Una buena síntesis de procedimientos y sistemas basados en el modelo se encuentra en MARTín López, María Teresa (2001). "Modelos de justicia juvenil: Análisis de derecho comparado". En: La responsabilidad penal de los menores, MarTín López, María Teresa (Coord.), Colección Estudios No 74, Universidad CastillaLa Mancha, Cuenca, pp. 79-89.
} 
Las razones tenidas en cuenta para ello emanan, en este caso, de la consideración de que las respuestas penales producen como efecto una reducción en las expectativas de reinserción o socialización del individuo como también cargan de manera negativa al individuo en su vida futura con el "estigma" o la "etiqueta" que es propia del proceso y la condena. Se reconoce con ello -a diferencia del positivismo- el contenido aflictivo de las reacciones procedentes, su fundamento centrado en la comisión de un delito y, consecuencialmente, que el Estado reacciona frente a ello (y debe reaccionar) con el ejercicio de instrumentos que forman parte del sistema de control del comportamiento punible. Asimismo, se proponen dinámicas de tratamiento o intervención sobre los adolescentes de carácter preventivo especial, dirigidas al fortalecimiento de aspectos asociados a índices de socialidad que se consideran deficitarios, sin llegar por ello a negar que el adolescente actúa en un marco de competencias autónomas suficientes para sostener su plena capacidad de respuesta. Se asume con ello que la noción de responsabilidad constituye un contenido útil para trabajar con el individuo de cara a la consecución de un comportamiento futuro respetuoso de las normas de convivencia y de los derechos de los demás.

Finalmente, es también destacable el que se procure incorporar la idea de tratamiento, reinserción o socialización en las propias fases ejecutivas de la pena, a través de lo cual se procura compatibilizar las necesidades preventivo generales que sirve el sistema con el particular énfasis que debe asignarse a los objetivos preventivo especiales en estos casos en forma especial, en atención a la caracterización natural que presenta el adolescente en cuanto individuo en pleno proceso de desarrollo y configuración de su personalidad (individual y social).

No obstante, pareciera que la modalidad específica que adopta la síntesis (de objetivos y presupuestos) que ofrece el modelo, no logra arribar a un punto satisfactorio, lo que se expresa concretamente en propuestas que plantean serias distorsiones en el logro de los objetivos que se desean alcanzar (que se declaran formalmente). Se trata, en el fondo, de un modelo que despliega mensajes equívocos e incentivos perversos que inciden en las reacciones que puede desarrollar el infractor, afectando con ello las perspectivas de éxito que pueden depositarse sobre su comportamiento actual o potencial ${ }^{46}$.

Por un lado, debemos destacar que el sistema propuesto opera sobre la base de la consideración de un amplio campo de decisiones confiadas a la discrecionalidad judicial o administrativa, fundado en el objetivo de incentivar en la mayor medida posible el acceso y la utilización de las medidas prejudiciales dispuestas

\footnotetext{
${ }^{46}$ En el mismo sentido Cruz Blanca, María José (2002). Derecho Penal de Menores (Ley Orgánica 5/2000 reguladora de la Responsabilidad Penal de los Menores). Madrid: Publicaciones del Instituto de Criminología de la Universidad Complutense de Madrid, No 87, p. 95.
} 
para el tratamiento del adolescente ${ }^{47}$. Con ello, se abre un espacio a riesgos de arbitrariedad del todo equivalente al que fuere denunciado respecto del modelo tutelar, constituyendo la desformalización de la intervención, en ambos casos, una base o presupuesto estructural en el funcionamiento que se propone para el sistema ${ }^{48}$. Hay que tener en cuenta que dicho marco de decisiones no sólo opera en las instancias de concesión o acceso a los respectivos programas de tratamiento, pues también operan a los efectos de resolver el curso que tendrá su ejecución, basado en la evaluación e individualización permanente de las necesidades de tratamiento, manteniéndose la respuesta punitiva, en todos los casos, absolutamente condicionada a dicho marco de discrecionalidad (judicial o administrativa).

De esta forma, en la práctica, lo que ofrece el modelo es la aplicación de un conjunto de medidas restrictivas, coactivas o que, cuando menos, consideran la asunción de obligaciones, que se imponen en términos prácticos en forma indeterminada (tanto en su contenido como en su duración) y de cuya satisfacción (confiada en una "amplia" valoración “discrecional') depende la continuación del proceso penal, la aplicación de medidas cautelares o, directamente, la imposición de una condena penal ${ }^{49}$. De esta forma, la desformalización se traduce en la pérdida prácticamente absoluta de las garantías formales que ofrece el sistema penal, planteada en función de una supuesta y adecuada mejor satisfacción de los objetivos preventivos, resultando difícilmente conciliable con las exigencias que emanan del Estado de derecho ${ }^{50}$.

En este contexto, a nadie debería extrañar la amplia "disposición a ser educado" que suele manifestar el infractor para lograr acceder a los mecanismos ofrecidos ${ }^{51}$,

\footnotetext{
${ }^{47}$ Sobre ello vid. MarTín López (2001), pp. 87 y ss.

${ }^{48}$ En el mismo sentido SILVA SÁNCHEZ manifiesta: "Las opciones a favor de la desjudicialización y de la desformalización, inspiradas en la humana pretensión de desdramatizar la intervención sobre los sujetos autores de los hechos antijurídicos en edades juveniles, suponen, por el contrario, una importante disminución de garantías". Vid. Silva SÁNChez (1997), p. 181.

${ }^{49}$ Con toda razón apunta GiménEZ-SAlinas (1993), p. 612, que el objetivo del modelo consistía en "no intervenir en interés del menor, es decir, justo la antitesis del modelo protector". Sin embargo, el modelo alcanza dicho objetivo sólo en lo que dice relación con la naturaleza punitiva de la intervención, excluyéndola, manteniendo y promoviendo la justificación positiva de las intervenciones que detenten naturaleza "educativa", siendo a veces difícil determinar en concreto el contenido coactivo que se impone bajo dicha pretensión.

${ }^{50}$ Lo dicho no debe ser entendido como una objeción a los espacios de intervención de la discrecionalidad judicial, del todo necesarios en estos conflictos, precisamente atendido a caracteres propios del adolescente. Dichos espacios, en el marco de un debido proceso, deben ejercitarse conforme a criterios contrastables que permitan conocer la racionalidad de la decisión adoptada. Asimismo, por y para el mismo fin, deben ser susceptibles de control. Normalmente ello se cumple con el establecimiento de una regla o parámetro de principios que deben orientar la resolución y la consagración de la obligatoriedad de fundamento de la misma, naturalmente, sobre la base de dicha regla. Ello permite que la decisión sea recurrible por defectos del fondo o forma (ausencia de fundamento), según sea el caso.

${ }^{51}$ Vid. Silva SÁnchez (1997), p. 180: "Un sistema respetuoso con las garantías individuales tiene que permitir la (negativa) del sujeto responsable al tratamiento, en la medida en que su hecho no tiene como base una ausencia de discernimiento".
} 
apuntando sus objetivos reales a lograr sortear el rigor del sistema. Si bien es cierto que dicha adhesión de fondo puede ser voluntaria, parece claro que la decisión que la motiva aparece fuertemente influenciada por el hecho de que se trata de la mejor opción disponible (o, mejor dicho, la menos mala o perjudicial), todo lo cual afecta sensiblemente a la cuota de compromiso personal real que pareciera requerir el modelo para alcanzar sus objetivos.

A esto se suma el que dicho mecanismo lleva implícito un criterio de selectividad que resulta muy difícil de conciliar con las exigencias del principio de igualdad. Se trata, en efecto, de que el modelo alternativo solo pareciera destinado a individuos que cuentan con un entorno social favorable a la aplicación de las medidas socioeducativas o de tratamiento, en términos que posibiliten el "pronóstico de recuperabilidad" en que se basa. Con ello, se condiciona la operatoria del sistema precisamente sobre la base de parámetros relativos a la situación o condición social del sujeto, asociados fundamentalmente a su nivel real o potencial de integración social, matizando con ello las consecuencias (naturaleza de la o las medidas) y la aplicación del sistema (el acceso a las mismas) con base en el origen socioeconómico, entorno, características y apoyo familiar con que cuente el infractor. Por lo mismo, quien cuenta con bases (antecedentes) o "credenciales de socialidad" que permitan un pronóstico favorable, será acreedor de una "medida indeterminada", "salvándose" de la pena. Por su parte, quienes se encuentren en el otro extremo serán sin duda acreedores de una sanción penal.

Sin embargo, los efectos asociados a esta constatación van más allá, en cuanto dicho componente no incide exclusivamente en el marco de las decisiones asociadas al acceso a las medidas de sustitución y sus contenidos. Se trata de un antecedente que en la mayoría de los casos determina también el resultado de su desarrollo, lo que lleva a que el sistema, inevitablemente, tienda a la autoconstatación.

A este respecto, conviene destacar que los resultados (estadísticos) que ofrece el modelo suelen ser relativamente alentadores, expresándose, en general, en análisis estadísticos que dan cuenta de la obtención de (bajos) índices de reincidencia o reiteración delictiva en los infractores a quienes se aplican las medidas de diversión. Se trata, sin embargo, de un resultado parcial de la aplicación del modelo, cuyos caracteres aparecen condicionados de antemano por el perfil de quienes tienen acceso a las dinámicas de carácter alternativo. De esta forma los resultados exitosos sólo aparecen conectados con el tratamiento de infractores de menor compromiso delictual ${ }^{52}$, aplicándose a los demás el sistema penal normal (en fórmulas normalmente propias del modelo clásico antes descrito, con tendencia a la sanción atenuada).

\footnotetext{
52 Vid. Tamarit Sumalla, Josep María (2001). "El Nuevo Derecho Penal de Menores ¿̨creación de un sistema penal menor?”. Revista Penal, No 8, p. 75. Oo. en Cruz BlanCa (2002), p. 185.
} 


\section{Modelo de Justicia o Responsabilidad esPecial (Doctrina DE LA PROTECCIÓN INTEGRAL de los Derechos DEL NiÑo)}

Las observaciones apuntadas respecto de los modelos clásico, tutelar y educativo, decantan, hacia finales de la década de los '80, en la configuración de un modelo alternativo, que pretende superar los déficits detectados, a partir de la estructuración de un sistema basado en el reconocimiento de los caracteres que naturalmente definen la interacción social de los adolescentes (reconocidos como una expresión normal o natural de esta etapa de la vida).

El denominado modelo de justicia o, lisa y llanamente, modelo de responsabilidad especial, se basa en la denominada doctrina de la protección integral de los derechos del niño, cuyo origen se vincula a los contenidos plasmados en la Convención Internacional sobre Derechos del Niño (1989) y otros instrumentos internacionales afines ${ }^{53}$. Este modelo asume la condición de ser sustentado hoy en día en forma ampliamente mayoritaria por la doctrina especializada en nuestro medio Iberoamericano ${ }^{54}$.

Dicha doctrina excede el marco de conflictos asociados a la responsabilidad penal de adolescentes, ofreciendo en todo caso premisas determinantes para la configuración que se propone para su tratamiento ${ }^{55}$. Se trata de contenidos que en su mayoría tienen la pretensión de incidir en la definición de todas las relaciones interpersonales que involucren a niños y adolescentes, sea con sus pares, con los adultos y, por supuesto, con los órganos del Estado ${ }^{56}$, marcando en este último caso la orientación, límites y objetivos irrenunciables de su actividad para con ellos ${ }^{57}$.

En lo relevante destacan entre dichos pilares el asumir como una exigencia que las facultades y la actividad de intervención del Estado para con los individuos (incluidos los menores de edad), se definan como una relación de derecho, caracte-

\footnotetext{
${ }^{53}$ Debe, además, considerarse el contenido de las Reglas mínimas para la administración de la justicia de menores (Beijing) (1985); de las Reglas mínimas para la protección de menores privados de libertad (1990) y de las Directrices de Naciones Unidas para la prevención de la delincuencia juvenil (RIAD) (1990).

${ }^{54}$ Vid. Martín López (2001), p. 91; Sánchez García de Paz (1998), pp. 110 y ss. Oo. en Pérez Martell, Rosa (2002). "El proceso penal del Menor. Ley Orgánica de Responsabilidad Penal del Menor". Revista de Derecho y Proceso Penal, Monografía No 5, Navarra: Aranzadi, pp. 65 y 90 y ss., quien, no obstante ello, propone un completo desarrollo de los presupuestos normativos expuestos en los diversos instrumentos internacionales referidos a la materia; asimismo, para un resumen del texto de las disposiciones pertinentes, vid. Couso y Duce (2013), pp. 301 y ss.

${ }^{55} \mathrm{~A}$ este respecto la fuente principal se ubica en los artículos 37 y 40.3 de la Convención Internacional sobre Derechos del Niño.

${ }^{56}$ Vid. Baratta, Alessandro (1999). "Infancia y Democracia”. En: Infancia Ley y Democracia en América Latina, García Méndez, Emilio y Beloff, Mary (Comps.), Buenos Aires: Temis-Depalma, p. 32.

${ }^{57}$ Así por ejemplo MARTín López (2001), pp. 153 y 155, señala: "En toda actuación de intervención con menores ha de tenerse muy en cuenta que se trata de sujetos de derecho, por lo que debe ser rechazada tanto una politica preventiva paternalista como una política exclusivamente dirigida al control o socialización programáticos por parte de los agentes estatales para con el niño o el adolescente".
} 
rizando los problemas frente a los cuales éste reacciona como conflictos de derecho, reservando para un lugar auxiliar (previo y no menos importante) el tratamiento social o asistencial comprometido ${ }^{58}$. Esto permite definir el papel que cumplen los órganos jurisdiccionales en la determinación de la responsabilidad concurrente a los actos delictivos ejecutados por adolescentes o menores de edad, en general, respecto de aquellos que ejecutan terceros en contra de sus derechos, separando ambas respuestas en modelos institucionales cuyos objetivos y características son perfectamente diferenciables (sistema de responsabilidad penal juvenil y sistema de protección de derechos de la infancia), lo que se denomina usualmente como "principio de separación de vías".

En este contexto, la respuesta penal constituye una exigencia asociada a necesidades preventivas, se legitima a partir de los presupuestos de actuación de los modelos penales y se basa en la atribución de responsabilidades individuales, constituyendo una reacción diversa a la que inspira la intervención del Estado dirigida a la protección de los derechos de los menores de edad y en el ámbito de la política social. A partir de esto, el modelo sostiene como exigencia el reconocimiento de todas las garantías procesales y penales procedentes frente a un conflicto de carácter penal, en equivalencia respecto de aquellas que son reconocidas a los adultos en estos mismos $\operatorname{casos}^{59}$. Lo que evidencia que en la configuración de los conflictos penales de adolescentes "la responsabilidad del joven [debe] pasa[r a ocupar necesariamente un] primer plano y el hecho cometido [debe ser] el punto de referencia del proceso y de las medidas a aplicar" 60.

Ello supone la legítima pretensión de hacer efectiva la responsabilidad en que incurren los menores de edad en caso que cometan delitos y con ello la legitimidad de aplicar consecuencias sancionatorias restrictivas de derechos sobre dicha base, fundado en el reconocimiento de la capacidad de autodeterminación que dichos individuos detentan en forma natural.

En efecto, al reconocer la titularidad de derechos subjetivos y la presencia de niveles importantes de ejercicio autónomo de los mismos, se asume la posibilidad de extraer consecuencias derivadas de la administración de dicha autonomía, incluyendo entre ellas, como base o fuente primaria, la responsabilidad que deriva

\footnotetext{
${ }^{58} \mathrm{Idem}$.

${ }^{59} \mathrm{La}$ mejor confirmación de ello lo reproducen los propios instrumentos internacionales y textos constitucionales que reconocen derechos individuales comunes a la especie humana, al señalar su atribución respecto de "toda persona", sin que en ello vaya establecido un elemento diferenciador en razón de la edad, como sucede por ejemplo en el encabezado del artículo 19 de la Constitución chilena y los artículos 6, 10 y, especialmente, 11.2 de la Constitución Política de la República del Ecuador. Con ello la conclusión es lógica: si se entiende que no le son aplicables dichos derechos, no se les reconoce el carácter de persona. Conforme a la nueva propuesta, al reconocerle el carácter de sujeto de derechos, las garantías que son propias de todo ser humano resultan plenamente aplicables a su respecto, y deben ser respetadas para atribuir a la intervención estatal legitimidad.
}

${ }^{60}$ Vid. Sánchez García de Paz (1998), p. 109. 
de su ejercicio individual. Al ser posible afirmar dicha responsabilidad se hace posible, a la vez, extraer de ella consecuencias ${ }^{61}$.

Sobre esta base se proscriben las resoluciones y medidas indeterminadas, que no guarden la debida proporcionalidad con el hecho imputado, el cual debe ser acreditado judicialmente en un proceso que goce de las garantías esenciales reconocidas a todos los individuos bajo el paradigma del debido proceso. Se proscribe, asimismo, la definición del contenido y presupuesto de la intervención al margen de dichas exigencias de legitimidad. Finalmente, se proscribe también la configuración de formas de intervención que desconozcan los límites que emanan del reconocimiento de la autonomía individual, particularmente de aquellas que pretendan incidir en los caracteres de la personalidad del individuo más allá del marco de decisiones que se encuentra amparado por dicho ejercicio. El adoctrinamiento o la administración de acciones destinadas a generar niveles de adhesión a formas de vida, patrones de conducta o formas de actuación, que vayan más allá del marco que ha sido definido como parte de la ilicitud, constituirían por ello formas de actuación incompatibles con el debido respeto que merece la autonomía individual, que se reconoce a los adolescentes como presupuesto esencial (y correlato) para requerirles (exigirles) los efectos asociados a su propia responsabilidad.

Ahora bien, dicho presupuesto se complementa con el reconocimiento de que dicha responsabilidad es necesariamente diversa a la que es posible extraer del comportamiento de un adulto, en tanto se asume que la caracterización de la personalidad de un adolescente es esencialmente diversa a la de un adulto en ámbitos que inciden directamente en la forma como opera el sistema de control penal y cuyos contenidos específicos ya hemos tenido ocasión de comentar ${ }^{62}$. Con ello, en el nivel formal, el Estado se encuentra habilitado (y en cierta forma obligado) a reconocer que los menores de edad cuentan con ámbitos donde pueden ejercer autónomamente sus derechos, lo que le permite hacer efectiva su responsabilidad. No obstante, dicha exigibilidad no es equivalente a la que puede reclamarse de un adulto, en la medida en que este último goza de autonomía plena para la administración completa de sus facultades individuales. En el nivel material el hecho de reconocer que el adolescente atraviesa por una etapa de desarrollo progresivo (principio de autonomía progresiva) cuyos caracteres inciden directamente en la forma como ellos procesan y reaccionan frente a las herramientas de que se sirve el Derecho Penal (normativas y materiales) lleva igualmente a delimitar una diferencia esencial que obliga a adaptar los contenidos y finalidades del sistema penal en forma coherente a dichas características ${ }^{63}$.

\footnotetext{
${ }^{61}$ Sobre ello vid. Ríos MarTín, Julián Carlos (1993). El menor infractor ante la ley penal. Granada: Comares, p. 227.

${ }^{62}$ Por todos, vid. Couso y Duce (2013), pp. 29 a 38 y pp. 301 y ss.

${ }^{63}$ En otro lugar, hemos tenido ocasión de hacernos cargo de una parte de dichos contenidos diferenciales y definitorios, incluyendo las citas de referencia que respaldan dicha caracterización. Al respecto vid. MALDONADO
} 
De esta forma, el menor de edad no es considerado como una persona incompleta o anormal, sino como un sujeto pleno, titular de derechos, pero diferente, que da forma a una categoría diversa de individuos que amerita, por lo mismo, un tratamiento diversificado. Ambos componentes dan forma al contenido de su responsabilidad especial, constituyendo referentes indispensables de tener en cuenta a la hora de definir los caracteres del modelo de intervención correspondiente ${ }^{64}$. Su omisión (de cualquiera) constituye por ello un déficit que llega a ser catalogado como una infracción de los derechos propios de los menores de edad ${ }^{65}$.

La consideración de estos contenidos debe cruzar toda la estructura del modelo de responsabilidad amparado en la doctrina de la protección integral, con incidencias que afectan a la caracterización de los presupuestos de la responsabilidad penal; de sus consecuencias y efectos en general y en la forma como se debe enfrentar su tratamiento procesal.

Particular claridad reviste esta cuestión en los aspectos nucleares del Derecho Penal sustantivo o material (presupuestos de la responsabilidad), esto es, en las diversas cuestiones a resolver en el marco de la teoría del delito, como también al revisar la ilicitud penal aplicable al régimen de adolescentes. Una mirada rigurosa permite sin grandes dificultades llegar a apreciar que el injusto penal juvenil presenta particularidades que demandan el uso de conceptos o parámetros diversos a los que el sistema está acostumbrado a ocupar en el modelo de adultos ${ }^{66}$. En lo concreto, ello se traduce en la necesidad de adecuar el criterio de medición que concurre tras una serie de elementos normativos (incluyendo los contenidos subjetivos del delito) a través de los cuales el legislador define los contornos del comportamiento

Fuentes, Francisco (2013). “Reincidencia y responsabilidad penal de adolescentes”. En: Estudios de Derecho Penal Juvenil, No IV, Centro de Documentación de la Defensoría Penal Pública, noviembre, pp. 192 y ss.; asimismo, con detalle, Couso Salas, Jaime (2012). "La especialidad del Derecho Penal de adolescentes. Fundamentos empíricos y normativos y consecuencias para una aplicación diferenciada del Derecho Penal sustantivo". Revista de Derecho de la Pontificia Universidad Católica de Valparaiso, XXXVIII, $1^{\text {er. }}$ semestre, pp. 272-285; vid., finalmente, Couso y DuCE (2013), pp. 24-39.

${ }^{64}$ Couso y Duce (2013), pp. 311 y ss.

${ }^{65}$ No está de más recordar que todos los instrumentos internaciones que dan forma a esta doctrina conforman un estatuto o corpus que pasa a integrar el contenido del artículo 19 de la Convención Interamericana de Derechos Humanos (Pacto de San José de Costa Rica) conforme al criterio sostenido por la Corte Interamericana de Derechos Humanos en los fallos Villagrán Morales, conocido como ‘niños de la calle (Guatemala), 1999; Walter Bulacio (Argentina) e "Instituto de reeducación superior Panchito López)" (Paraguay), y en la Opinión Consultiva No 17 de la Corte Interamericana: "Condición Jurídica y Derechos Humanos del Niño" (2002), instrumento interpretativo de validez general. Bajo estas premisas la competencia de los órganos del pacto no parece discutirse. Al respecto vid. DuCE Julio, Mauricio (2009). "El derecho a un juzgamiento especializado de los jóvenes infractores en el Derecho Internacional de los Derechos Humanos y su impacto en el diseño del proceso penal juvenil”. Ius et Praxis, Año 15, No 1, pp. 77 y ss.

${ }^{66}$ Vid. Couso y Duce (2013), pp. 311 y ss. Hernández Basualto (2007), p. 198, quien destaca que el recurrir a estos contenidos materiales constituye una tarea forzosa. 
punible $^{67}$. Para ser más concreto, y sin pretensiones de ser exhaustivo, se trata de modificar el criterio a utilizar a la hora de medir el cuidado debido en los delitos culposos, la interpretación de los deberes asociados al comportamiento omisivo y la valoración de las reglas de exigibilidad asociadas a la culpabilidad (p. ej., a la hora de valorar la suficiencia del miedo insuperable $)^{68}$. También debemos considerar que un amplio campo de los delitos previstos en la legislación en general carecen de toda relevancia en el plano adolescente, ya sea porque objetivamente alguno de sus presupuestos excluye la posibilidad de que un adolescente incurra en ellos o porque, materialmente, dicha alternativa se torna difícil de configurar, lleva a resultados incongruentes o, finalmente, irracionales. Puede a este respecto mencionarse de manera ejemplar el caso de los delitos de connotación sexual estructurados como figuras de prevalimiento bajo el amparo de la incapacidad sexual de los menores de edad (comúnmente englobados bajo la rúbrica de la indemnidad sexual) ${ }^{69}$, la sustracción de menores de edad; la inducción al abandono de hogar; los delitos funcionarios donde el contenido de injusto radica en la infracción de deberes inherentes a dicha condición, entre otros.

Asimismo, y con un grado mayor de profundidad, se debe tener en cuenta que para los adolescentes el sentido de determinados comportamientos puede ser diverso al que es propio de un adulto en su relevancia o significado concreto, adquiriendo naturalmente $-\mathrm{y}$ eso es lo importante- una perspectiva que puede ser diversa a la prevista por el legislador a partir del mismo contenido y de los elementos que han sido considerados en la tipificación de un delito ${ }^{70}$. Con ello, parece posible sostener la necesidad de llevar a cabo una valorización diversa de la adecuación social en determinados comportamientos, con independencia de que sean en general considerados punibles desde la perspectiva de un adulto. Lo determinante es el significado individual y social que dichas conductas detentan en el contexto en que se producen, siendo factible asignarle una relevancia diferenciada a factores como la modalidad de interacción (p. ej., en atención a las condicionantes concurrentes en los adolescentes en torno a la actuación en pandilla o masas) o al rol que juega en sus particulares representaciones el actuar rozando los límites de lo permitido (p. ej., en base a la trascendencia en dicha etapa del comportamiento experimental). Ahora bien, conviene aclarar que esta dinámica no opera en exclusiva dirección a la

\footnotetext{
${ }^{67}$ Vid. Couso Salas, Jaime (2008). "Notas para un estudio sobre la especialidad del Derecho Penal y procesal penal de adolescentes: El caso de la Ley chilena". En: Justicia y derechos del niño, No 10, p. 106; Maldonado Fuentes (2009), pp. 140-141.

${ }^{68} \mathrm{Vid}$. Couso Salas (2008), p. 107. Parafraseando, se trata de orientar la decisión por la actuación esperable del adolescente medio, que no necesariamente equivale al criterio general (hombre medio).

${ }^{69}$ Vid. HeRnández Basualto (2007), p. 203, quien menciona por vía ejemplar la producción de material pornográfico en el que participan los propios adolescentes o el favorecimiento de la prostitución, entendiendo que son figuras que se sancionan a partir del aprovechamiento o explotación que desarrollan sujetos adultos. En el mismo sentido, Couso Salas (2008), p. 106.

${ }^{70}$ Vid. Couso Salas (2008), p. 105.
} 
exclusión de presupuestos de imputación, esto es, reflejándose en un resultado que siempre se traduzca en una condición más favorable para el adolescente (eximente o aminorante de la responsabilidad). Sus particulares condiciones también permiten desarrollar una valorización de los elementos y circunstancias del delito que se traduzca en la atribución de una relevancia diversa a la que tiene su significado en las reglas generales. También la averiguación del sentido particular de determinados contenidos o elementos puede llevar a asignarles un papel más trascendente en relación al que representan en el comportamiento general de un adulto. Así sucede, por ejemplo, con el carácter violento que pudiere revestir el comportamiento punible. Constituyen, en tal virtud, elementos de juicio que cobran un especial cariz a la hora de valorar las consecuencias de la responsabilidad penal ${ }^{71}$.

Todo lo anterior hace aconsejable contar con una descripción específica y acotada de los comportamientos (y sus caracteres esenciales) donde parece necesario recurrir al sistema de control penal, y evitar, en la medida de lo posible, incurrir a este respecto en remisiones automáticas o generales a la legislación penal general (de adultos).

En el ámbito de las consecuencias la necesidad de asignarle un tratamiento especial obliga a orientar las diversas intervenciones acorde al binomio autonomíadesarrollo progresivo. A este respecto conviene revisar la afirmación habitual de que la pena dispuesta para los adolescentes se rige fundamental y prioritariamente por criterios de prevención especial (resocialización) o educativos ${ }^{72}$, afirmación que pareciera de suyo desdibujar las consideraciones que se brindan a la prevención general y, sobre todo, a la idea de culpabilidad ${ }^{73}$. El punto está en que la supremacía absoluta de dichos objetivos lleva directamente a la instauración de un modelo que no se diferencia de los contenidos propuestos por el correccionalismo (doctrina tutelar) y en la aplicación de criterios que inevitablemente terminan rindiendo tributo a la incapacidad de desenvolvimiento social del adolescente. En particular, lleva a la pretensión de orientar la intervención hacia la corrección de su forma de vida a partir de parámetros de relación propios de la sociedad de adultos, finalidad que nutre de contenido a la idea de normalizarlo ${ }^{74}$. En términos coloquiales, suele

\footnotetext{
${ }^{71} \mathrm{Al}$ respecto vid. específicamente el contenido del artículo 7.1 letra c) de las "Reglas de Beijing".

${ }^{72}$ Albrecht, Peter-Alexis (1990). El Derecho Penal de Menores. Bustos Ramírez, Juan (Trad.), Barcelona: PPU, p. 348.

${ }^{73} \mathrm{Al}$ respecto Couso SALAS, Jaime (2005) "Principio educativo y (re)socialización en el Derecho Penal juvenil". Revista de Derecho del Consejo de Defensa del Estado, No 14, p. 66, señala: "es frecuente (...) que los argumentos preventivo-especiales se empleen para imponer una sanción o medida en casos en que a un adulto no se le habría impuesto, o para imponerle una más intensa en su injerencia en las libertades del adolescente".

${ }^{74}$ Albrecht (1999), p. 349: "También en la medición de la pena, el principio de reducación se ha mostrado como criterio poco racional. Ha surgido como categoría encubridora legitimante (...) la reducación sirve ampliamente como sinónimo para represión y prevención general (...) no es capaz de servir para la imposición ni para la medición de la pena de menores como principio directriz suficiente conforme a las exigencias de un Estado de Derecho".
} 
pretenderse con ello actuar sobre el adolescente para transformarlo en un buen adulto, uno que cumpla con las reglas de comportamiento social adecuadas, en lugar de intervenir para que sea un buen adolescente.

Dicha orientación (así entendida) resulta incompatible con la afirmación o reconocimiento de una base de autonomía, condición inexcusable en una estructura que le reconoce titularidad en el ejercicio de derechos subjetivos, como aquella que emana del reconocimiento de su carácter de sujeto de derechos ${ }^{75}$.

Sobre esta base parece claro que el desafío que dicha condición propone se traduce en la necesidad de compatibilizar las particulares condiciones que lo caracterizan de manera definitoria o esencial, y particularmente, el hecho de que se trata de sujetos en fase de formación (esto es, en plena consolidación de las definiciones propias de su personalidad y de sus habilidades de relación e interacción), con el contenido de autonomía que les debe ser reconocido en términos igualmente propios, lo que lleva a la configuración de una responsabilidad que sea propia del adolescente (diversa o especial $)^{76}$. Se trata de depurar la forma como se pueden considerar los aspectos personales señalados en un marco que considera la presencia de un campo que pasa a caracterizarse por una amplia libertad de decisión, lo que lleva a modificar la forma tradicional de comprensión de la lógica de la inserción social. Ello supone, por una parte, asignar un mayor énfasis a la función limitativa asociada a los efectos desocializadores de la sanción penal, en cuanto la restricción de derechos minimiza las opciones de llevar a cabo de manera regular la transición que supone la adolescencia, con efectos -negativos- que pueden revestir carácter permanente ${ }^{77}$. Pero además, supone considerar de forma obligatoria contenidos de reemplazo o sustitución de las condiciones de desarrollo de dicho proceso de construcción individual que se ven interrumpidos o alterados por la imposición y ejecución de una pena (escolarización, relaciones interpersonales, etc.) posibilitando de esta forma que dicho proceso continúe, se consolide o refuerce (en caso de ser necesario o deficitario) ${ }^{78}$.

El primero de dichos aspectos incide indistintamente en las dimensiones cuantitativas y cualitativas de la sanción, reduciendo su índice de aflictividad en comparación con el de un adulto, tanto en lo referido a la extensión de la respuesta como en lo atingente a su naturaleza, rigiendo en ambos casos el mismo marco de relación que el Estado tiene con los individuos en el medio libre. Desde dicha perspectiva, la pena tiene siempre una incidencia en las decisiones futuras del sujeto, pero sin llegar a sustituirlas. Así, por ejemplo, la cárcel (sin modalidad

\footnotetext{
${ }^{75}$ Una perspectiva diversa en MañAlich RafFo (2013), pp. 219 y ss.

${ }^{76}$ Von Hirsch (2012), p. 77.

${ }^{77}$ Vid. Couso y Duce (2013), pp. 36 y ss. Von Hirsch (2012), p. 73.

${ }^{78}$ Lo dicho se aplica a los casos en que la naturaleza y características de la sanción producen materialmente dicho efecto. En consecuencia, en los demás casos, se debe privilegiar su continuidad bajo las modalidades y formas que lo caracterizaban.
} 
alguna de intervención) y buena parte de las medidas no privativas de libertad en el sistema de adultos deja al entero arbitrio del condenado el "aprender la lección" siendo una cuestión del todo suya el asumir y controlar el riesgo de reincidencia. Se podrá apreciar que la consideración voluntaria de instancias de socialidad en las fases de ejecución sigue la misma lógica, encontrándose más o menos asentada la idea de que debe en este plano rechazarse su imposición coactiva. En el sistema de adolescentes dicha base (incluyendo la voluntariedad) no se modifica constituyendo las razones apuntadas el único fundamento que hace necesario y exigible es el contar con dicha orientación en los contenidos de la ejecución ${ }^{79}$.

Por su parte, el segundo de dichos aspectos parece más bien acotar su influencia a los aspectos cualitativos de la reacción penal, potenciando directamente la presencia e incorporación de elementos positivos asociados a la idea de la inserción social (reinserción, socialización, o cualquier término análogo, asociado a prevención especial positiva) en el contenido que caracteriza a la intervención penal de adolescentes. Lo más relevante, sin embargo, es que dicha incidencia no implica en modo alguno modificar los términos bajo los cuales el Estado acomete su relación y posicionamiento para con el individuo, constituyendo un presupuesto y un objetivo que no le permite llegar a sobrepasar el reconocimiento de la autonomía y voluntad del adolescente, en cuanto supondría sustituirlo en un proceso de desarrollo personal (formación individual, consolidación de su personalidad, etc.) que se define como autónomo.

En términos simples, no se trata de arribar a una pena más corta, de naturaleza menos aflictiva (aspectos que de por sí ya están considerados por razones de proporcionalidad y necesidad de pena), pero más invasiva o interventora, sino precisamente a una que introduce elementos en la ejecución que favorecen la incorporación de contenidos asociados a socialidad sin modificar o comprometer la debida autonomía que se debe reconocer al adolescente ${ }^{80}$.

Esta precisión permite reforzar todo tipo de nociones relativas a la autorresponsabilidad en el contenido material de las sanciones dirigidas a adolescentes, la asunción de deberes, aceptación de los mismos, ética de la responsabilidad, etc., todo ello a partir de valoraciones centradas en la conciencia del daño individual y social vinculado al delito ${ }^{81}$. Permite asimismo suprimir pretensiones de

\footnotetext{
${ }^{79}$ En el mismo sentido Couso y Duce (2013), pp. 392 y 393.

${ }^{80}$ Elocuentes son los siguientes términos de Couso SALAS (2005), p. 65: “(...) en la cuestión de la pena preventivo-especial el problema constitucional que afecta a los menores de edad no tiene nada que ver con el derecho a la educación sino con el derecho a la autonomía moral, la dignidad y el libre desarrollo de la personalidad (...) la cuestión del consentimiento del adolescente en el tratamiento (re)educador o (re)socializador se vuelve una exigencia fundamental, tal como lo es para el condenado adulto", con cita de referencia a Roxin.

${ }^{81}$ Para Cillero Bruñol (2009), p. 22, dichos contenidos operan en términos limitativos, en cuanto nunca pueden servir para fundar la imposición de la pena. Sintéticamente, debemos agregar que sostiene su tesis en la eventualidad de que dicho expediente lleve a excesos paternalistas.
} 
inculcación coactiva de conceptos o formas de vida, en todo lo que vaya más allá de una oferta, definida en términos equivalentes a como se desarrolla en medio libre, en condiciones de normalidad. Por lo mismo, permite potenciar el uso de las alternativas (o sustitutivos penales y del proceso) y en general todos los efectos que pueden asociarse a una incrementada óptica de la mínima intervención (como, por ejemplo, la utilización de la privación de libertad como último recurso). Finalmente, permite evitar los efectos asociados a la falta de consideración de los objetivos preventivo generales, sea por exceso o por defecto. Así, refuerza la idea de que el Estado debe reaccionar, como también el que no puede hacerlo por razones preventivo especiales (como la pretensión resocializadora), más allá del marco de la propia culpabilidad.

Resumiendo, se trata de contenidos que no alteran la consideración que debe brindarse en el ámbito de las funciones de la pena a las necesidades de prevención general comprometidas y a los efectos limitativos que emanan de la idea de culpabilidad (en cuanto herencia del retribucionismo), resultando estos últimos incluso reforzados. Las modificaciones corren entonces de la mano de las expresiones preventivo-especiales, con alteraciones que principalmente afectan los contenidos y, en su caso, hacen más clara la forma de resolución de las antinomias, en aquellos casos en que los presupuestos derivados de la especialidad se hagan presentes y así lo demanden ${ }^{82}$.

En otro ámbito, no podemos dejar de mencionar que los caracteres de la personalidad del adolescente en lo relativo a su variabilidad o a la orientación hacia la reinserción también generan efectos dignos de destacar. Por un lado, refuerzan el uso preferente de medidas de "diversión"; motivan la consideración de un amplio catálogo de sanciones posibles de aplicar, la consagración de un sistema de determinación de la sanción en base a reglas de principios donde opera en forma preferente la resolución fundada en la discrecionalidad judicial; obligan a determinar la progresión en la ejecución de las sanciones con instancias dirigidas a la revisión de la pertinencia de su mantención, con posibilidades de sustitución o incluso de revocación de medida. Finalmente, obligan asimismo, a la brevedad del proceso $^{83}$.

\footnotetext{
${ }^{82}$ Por ello, cualquier antecedente que vaya más allá del contenido que es propio del proceso de desarrollo y consolidación personal del adolescente, no debe ser considerado a estos efectos. De ahí que se excluyan aspectos sociales, familiares o de condición económica que pudieren generar efectos discriminatorios.

${ }^{83}$ Cabe destacar que las medidas de diversión y el sistema de individualización de la sanción admiten espacios al ejercicio de facultades discrecionales que deben ser ejercidas en el contexto que le da fundamento a su consideración en el sistema, esto es, en este caso, bajo el principio del interés superior del niño. No se trata por ende, de optar por una medida alternativa al proceso o en aplicar el principio de oportunidad o, finalmente, en disponer el cumplimiento de un trabajo comunitario, en atención a que ello "favorece la educación del niño o adolescente". Se trata de adoptar dicha decisión en tanto constituye la alternativa de responsabilidad -y esto lo diferencia del sistema educativo- que en mejor forma concilia el respeto a sus derechos como persona en desarrollo.
} 


\section{BiBLIOGRAFÍA CITADA}

Albrecht, Peter-Alexis (1990). El Derecho Penal de Menores. Bustos Ramírez, Juan (Trad.), Barcelona: PPU.

Baratta, Alessandro (1999). "Infancia y Democracia”. En: Infancia Ley y Democracia en América Latina, GarCía Méndez, Emilio y Beloff, Mary (Comps.), Buenos Aires: Temis-Depalma.

Cervelló Donderis, Vicenta y Colás Turégano, Asunción (2002). La responsabilidad penal del menor de edad. Madrid: Tecnos.

Cillero Bruñol, Miguel (1999). "El Interés Superior del Niño en el marco de la Convención Internacional sobre los Derechos del Niño". En: Infancia Ley y Democracia en América Latina, García Méndez, Emilio y Beloff, Mary (Comps.), Buenos Aires: Temis-Depalma, pp. 69-85.

Cillero Bruñol, Miguel (2002). "Artículo 10 No 2 y 3". En: Texto y Comentarios del Código Penal chileno, Politoff, Sergio y Ortiz, Luis (Dirs.), Matus, Jean Pierre (Coord.), Tomo I, Libro Primero, Parte General, Santiago: Editorial Jurídica de Chile.

Cillero Bruñol, Miguel (2008). "Consideraciones para la aplicación del criterio de idoneidad en la determinación de las sanciones en el Derecho Penal de adolescentes chileno". Documento de Trabajo No 13, Unidad de Defensa Penal Juvenil, Defensoría Penal Pública. Posteriormente publicado en una versión corregida bajo el título "Proporcionalidad y fines de la sanción penal de adolescentes: consideraciones para la aplicación del criterio de idoneidad de la sanción". En: Estudios de Derecho Penal Juvenil I, Centro de Documentación de la Defensoría Penal Pública, serie Informes en Derecho No 5, noviembre 2009, pp. 137-171.

Couso Salas, Jaime (1999). Derecho Penal de adolescentes: ¿educación, ayuda o sanción? Facultad de Ciencias Sociales de la Universidad de Chile-UNICEF, Santiago.

Couso Salas, Jaime (2002). "Problemas teóricos y prácticos del principio de separación de medidas y programas, entre la vía penal-juvenil y la vía de protección especial de derechos". En: De la tutela a la Justicia, Documentos de Estudio Corporación Opción, Santiago, pp. 65-95.

Couso Salas, Jaime (2005) "Principio educativo y (re)socialización en el Derecho Penal juvenil”. Revista de Derecho del Consejo de Defensa del Estado, No 14, pp. 57-72.

Couso Salas, Jaime (2008). "Notas para un estudio sobre la especialidad del Derecho Penal y Procesal Penal de Adolescentes: El caso de la Ley chilena”. En: Justicia y derechos del niño, No 10, pp. 97-112.

Couso Salas, Jaime (2011). "Sustitución y remisión de sanciones penales de adolescentes. Criterios y límites para las decisiones en sede de control judicial 
de las sanciones". En: Estudios de Derecho Penal Juvenil II, Informes en Derecho, Centro de Documentación de la Defensoría Penal Pública, diciembre, pp. 269-355.

Couso Salas, Jaime (2012). "La especialidad del Derecho Penal de adolescentes. Fundamentos empíricos y normativos y consecuencias para una aplicación diferenciada del Derecho Penal sustantivo". Revista de Derecho de la Pontificia Universidad Católica de Valparaíso, XXXVIII, ${ }^{\text {er. }}$ semestre, pp. 267-322.

Couso, Jaime y Duce, Mauricio (2013). Juzgamiento penal de adolescentes. Santiago: LOM.

Cruz Blanca, María José (2002). Derecho Penal de Menores (Ley Orgánica 5/2000 reguladora de la Responsabilidad Penal de los Menores). Madrid: Publicaciones del Instituto de Criminología de la Universidad Complutense de Madrid, No 87.

Cruz Márquez, Beatriz (2012). "La culpabilidad por el hecho del adolescente: referencias y diferencias respecto del Derecho Penal de adultos". En: Estudios de Derecho Penal Juvenil III, Informes en Derecho No 11, Centro de Documentación de la Defensoría Penal Pública, Santiago, pp. 9-32.

De Figueiredo Dias, Jorge (2004). Direito Penal. Parte Geral. Lisboa: Coimbra Editora.

DuCE Julio, Mauricio (2009). "El derecho a un juzgamiento especializado de los jóvenes infractores en el Derecho Internacional de los Derechos Humanos y su impacto en el diseño del proceso penal juvenil”. Ius et Praxis, Año 15, No 1, pp. 73-120.

DüNKEL, Frieder (2001). "Reacciones en los campos de la administración de justicia y de la pedagogía social a la delincuencia infantil y juvenil: Un estudio comparativo a escala europea”. En: La responsabilidad penal de los menores: Aspectos sustantivos y procesales", ORNOSA FERNÁNDEZ, María del Rosario (Dir.), Cuadernos de Derecho Judicial, No III, pp. 119-186.

Fletcher, George (1997). Problemas básicos del Derecho Penal. Valencia: Tirant lo Blanch.

García Méndez, Emilio (1997). Derecho de la Infancia-Adolescencia en América Latina. De la situación irregular a la protección integral. Tolima: Forum-Pacis, 2a edición.

García Méndez, Emilio (2004). Infancia. De los derechos y de la justicia. Buenos Aires: Editores del Puerto, 2a edición actualizada.

GiméneZ-Salinas I Colomer, Esther (1993). "La mayoría de edad penal en la reforma". En: Homenaje a Juan del Rosal, Madrid: Editoriales de Derecho Reunidas, pp. 607-645.

Gomes Da Costa, Antônio Carlos (1997). "Pedagogía y justicia”. En: Infancia Ley y Democracia en América Latina, García Méndez, Emilio y Beloff, Mary (Comps.), Buenos Aires: Temis-Depalma. 
Hernández Basualto, Héctor (2007). "El nuevo Derecho Penal de adolescentes y la necesaria revisión de su teoría del delito". Revista de Derecho Universidad Austral de Valdivia, Vol. XX, No 2, diciembre, pp. 195-217.

Horvitz Lennon, María Inés (2006). "Determinación de las sanciones en la ley de responsabilidad penal juvenil y procedimiento aplicable”. Revista Estudios de la Justicia, No 7, pp. 97-119.

Landrove Díaz, Gerardo (2001). Derecho Penal de Menores. Valencia: Tirant lo Blanch.

Maldonado Fuentes, Francisco (2004). "La especialidad del sistema de responsabilidad penal de los adolescentes. Reflexiones acerca de la justificación de un tratamiento penal diferenciado". Revista Justicia y Derechos del Niño, No 6, pp. 103-160.

Maldonado Fuentes, Francisco (2009). "Responsabilidad penal juvenil: estado actual y perspectivas". Disponible en: ‘www.microjuris.com), cita: $\mathrm{MJCH}_{-}$ MJD372 | MJD372. Una versión levemente actualizada ha sido publicada en Revista General de Derecho Penal, No 14, noviembre 2010.

Maldonado Fuentes, Francisco (2011). "Fundamentación y determinación de la pena en el Derecho Penal de adolescentes. A propósito del Juicio seguido contra B. N. M. Por delito de robo con intimidación (Ruc 0900505404-1) en la V Región". Ius et Praxis, año 17, No 2, pp. 505-536.

Maldonado Fuentes, Francisco (2013). "Reincidencia y responsabilidad penal de adolescentes". En: Estudios de Derecho Penal Juvenil, No IV, Centro de Documentación de la Defensoría Penal Pública, noviembre, pp. 169-212.

Mañalich Raffo, Juan Pablo (2013). "Los plazos de prescripción de la acción penal de la ley de responsabilidad penal de adolescentes frente al artículo 369 quáter del Código Penal”. En: Estudios de Derecho Penal Juvenil IV, Informes en Derecho No 13, Centro de Documentación de la Defensoría Penal Pública, Santiago, pp. 213-232.

Martín López, María Teresa (2001). "Modelos de justicia juvenil: Análisis de derecho comparado". En: La responsabilidad penal de los menores, MARTín LÓPEZ, María Teresa (Coord.), Colección Estudios No 74, Universidad Castilla-La Mancha, Cuenca, pp. 67-104.

Ornosa Fernández, María Rosario (2003). Derecho Penal de Menores. Comentarios a la Ley Orgánica 5/2000, de 12 de enero, Reguladora de la Responsabilidad Penal de los Menores. Barcelona: Bosch, 2a edición.

Pacheco, Joaquín Francisco (1888). El Código Penal concordado y comentado. Madrid, Tomo I, 6a edición.

Pérez Martell, Rosa (2002). “El proceso penal del Menor. Ley Orgánica de Responsabilidad Penal del Menor". Revista de Derecho y Proceso Penal, Monografía No 5, Navarra: Aranzadi. 
Piña Rochefort, Juan Ignacio (2010). Derecho Penal. Fundamentos de la responsabilidad. Santiago: AbeledoPerrot.

Ríos Martín, Julián Carlos (1993). El menor infractor ante la ley penal. Granada: Comares.

Sánchez García de Paz, Isabel (1998). Minoría de edad penal y Derecho Penal juvenil. Granada: Comares.

Silva Sánchez, Jesús María (1997). "El régimen de la minoría de edad penal". En: El Nuevo Código Penal: Cinco Cuestiones Fundamentales, Barcelona: Bosch, pp. 159-195.

Tamarit Sumalla, Josep María (2001). "El Nuevo Derecho Penal de Menores ¿creación de un sistema penal menor?”. Revista Penal, No 8, pp. 71-89.

Vives Antón, Tomás Salvador (1995). “Constitución y Derecho Penal de Menores”. En: La Libertad como Pretexto, Valencia: Tirant lo Blanch.

VON Hirsch, Andrew (2012). "Sentencias proporcionales para menores ¿qué diferencia con las de los adultos?". En: Estudios de Derecho Penal Juvenil III, Informes en Derecho No 11, Centro de Documentación de la Defensoría Penal Pública, Santiago, pp. 61-85.

Zaffaroni, Eugenio Raúl (2002). Derecho Penal. Parte General. Buenos Aires: Ediar, 2a edición. 